\title{
Inductively coupled plasma: Fundamental particle investigations with laser ablation and applications in magnetic sector mass spectrometry
}

by

\author{
Nathan Joe Saetveit \\ A dissertation submitted to the graduate faculty \\ DOCTOR OF PHILOSOPHY \\ Major: Analytical Chemistry \\ Program of Study Committee: \\ Robert S. Houk, Major Professor \\ Jacob W. Petrich \\ Emily A. Smith \\ Hans U. Stauffer \\ Patricia A. Thiel
}

in partial fulfillment of the requirements for the degree of

Iowa State University

Ames, lowa

2008

Copyright (C) Nathan Joe Saetveit, 2008. All rights reserved. 


\section{Table of Contents}

Abstract

Chapter 1. Introduction 1

General Introduction $\quad 1$

Laser Ablation 1

Elemental Fractionation $\quad 1$

Energy Density 2

Wavelength $\quad 3$

Pulse Duration 3

Motion of the Laser Beam 3

Carrier Gas 4

ICP-induced Fractionation $\quad 5$

Magnetic Sector Mass Spectrometry 5

$\begin{array}{ll}\text { Dissertation Organization } & 6\end{array}$

$\begin{array}{ll}\text { References } & 7\end{array}$

Chapter 2. Influence of particle size on fractionation with nanosecond and femtosecond laser ablation in brass by online differential mobility analysis and inductively coupled plasma mass spectrometry 11

$\begin{array}{ll}\text { Abstract } & 11\end{array}$

$\begin{array}{ll}\text { Introduction } & 11\end{array}$

$\begin{array}{ll}\text { Experimental } & 14\end{array}$

Laser Ablation $\quad 14$

Differential Mobility Analyzer $\quad 15$

ICP-MS 15

Samples and Conditions $\quad 15$

$\begin{array}{ll}\text { Data Analysis } & 17\end{array}$

$\begin{array}{ll}\text { Results and Discussion } & 17\end{array}$

System Noise Analysis from Isotope Ratios $\quad 17$

$\begin{array}{ll}\text { Nanosecond LA } & 18\end{array}$

Femtosecond LA 19

Plasma Loading Effects $\quad 20$ 
Tables

Figures

Chapter 3. High-speed digital photographic study of an inductively coupled plasma: Single particle behavior from solution nebulization and laser ablation

Abstract

Introduction

Experimental

ICP Conditions

Photographic Equipment and Parameters

Laser Ablation

Samples and Conditions

Results and Discussion

Introduction of Large, Wet Droplets

Laser Ablation of $\mathrm{Y}_{2} \mathrm{O}_{3}$

Emission Profiles from $\mathrm{Na}, \mathrm{Ca}$, and $\mathrm{Si}$

Laser Ablation on NIST 610 Glass

Particle Velocity

Conclusions

Acknowledgements

References

Figures 
Chapter 4. A method for online detection of elemental release from live tissue in a physiological saline matrix using inductively coupled plasma mass spectrometry

Abstract

Introduction

Experimental

Chemicals and Materials

66

Cleaning Procedures

67

Solution Preparation

Slice Chamber and Flow System

Sample Introduction

Instrumentation

Data Analysis

Results and Discussion

Peak Position

Sample Pathway

72

Time Profiles

73

Limit of Detection

Conclusions

Acknowledgements

References

Tables

Figures 


\begin{abstract}
Particle size effects and elemental fractionation in laser ablation inductively coupled plasma mass spectrometry (LA-ICP-MS) are investigated with nanosecond and femtosecond laser ablation, differential mobility analysis, and magnetic sector ICP-MS. Laser pulse width was found to have a significant influence on the LA particle size distribution and the elemental composition of the aerosol and thus fractionation. Emission from individual particles from solution nebulization, glass, and a pressed powder pellet are observed with high speed digital photography. The presence of intact particles in an ICP is shown to be a likely source of fractionation. A technique for the online detection of stimulated elemental release from neural tissue using magnetic sector ICP-MS is described. Detection limits of 1 $\mu \mathrm{g} \mathrm{L}^{-1}$ or better were found for $\mathrm{P}, \mathrm{Mn}, \mathrm{Fe}, \mathrm{Cu}$, and $\mathrm{Zn}$ in a $60 \mu \mathrm{L}$ injection in a physiological saline matrix.
\end{abstract}




\section{Chapter 1. Introduction}

\section{General Introduction}

Inductively coupled plasma mass spectrometry (ICP-MS) is a popular analytical tool for elemental analysis. ${ }^{1-3}$ An ICP is an atmospheric pressure ionization source well suited for combination with MS for the rapid determination of many elements in a wide variety of samples with detection limits often in the low part per trillion (ppt) range or better. ${ }^{3}$

When an aerosol is introduced into an ICP, three main processes occur: vaporization, atomization, and ionization. The relatively high temperature of a typical ICP $(6000 \mathrm{~K}-8000$ $\mathrm{K}$ ) is very effective at vaporizing, atomizing, and ionizing sample atoms. ${ }^{3}$ Many sampling methods are available for analyses with ICP-MS. Commonly, liquid samples are nebulized into a spray chamber and the resulting aerosol is injected into an ICP. ${ }^{4}$ For solid samples, laser ablation (LA) is frequently used to remove a small amount of material for introduction into the ICP. ${ }^{5-7}$

\section{Laser Ablation}

\section{Elemental Fractionation}

During LA-ICP-MS, a laser beam is focused on the surface of a solid sample in a closed cell, and the ablated material is transported in a carrier gas through tubing into an ICP. Although LA-ICP-MS has been used for the analysis of solids for over 20 years, ${ }^{5}$ some fundamental processes are yet to be understood. In particular, elemental fractionation, defined in this work as a discrepancy between the actual stoichiometry of a sample and the experimentally determined elemental ratios, continues to hinder analyses by LA, especially 
for work with nanosecond lasers. Fractionation may occur during the ablation process, transport to the ICP, or vaporization in the ICP. ${ }^{8,9}$ The presence and size of particles formed during LA and introduced into the ICP have been implicated as an important source of fractionation in LA-ICP-MS. ${ }^{8,10-14}$

A main cause of fractionation is the mechanism of vaporization. ${ }^{9}$ When aerosol is created during LA, different laser conditions may cause particles to form in specific ways, leading to laser-induced fractionation. For example, as vapor from a LA event cools, elements with different volatilities may not condense into stoichiometric particles. Several parameters in LA affect the composition of the aerosol and thus fractionation, including laser energy, wavelength, pulse duration, motion of the beam during ablation (i.e. single hole ablation versus raster ablation), and the type of carrier gas used to transport the ablated material to the ICP. ${ }^{9-11,15-26}$

\section{Energy Density}

At the threshold of ablation, when the laser energy density is just great enough to begin melting and vaporizing the surface of the sample, there is very little particle formation. As the energy density of the laser beam is increased, however, the ablation process becomes more violent and ejects more material from the surface. In the ablation laser energy density regime typically used for analysis, a plume of vapor and molten particulates is ejected from the surface of the solid on the nanosecond time scale. During a typical laser pulse of $5 \mathrm{~ns}$, this plume has ample time to interact with the laser beam and absorb a portion of the energy

from the beam. ${ }^{10}$ Some of this energy serves to ionize the material (inconsequential ionization when considering ICP-MS), but there is also enough energy to cause some melting 
and agglomeration of particulates. This process, along with particles ejected from the surface, contributes to the presence of a particle size distribution entrained in the flow of carrier gas going to the ICP.

\section{Wavelength}

Laser wavelength has a great influence on ablation and the resulting particle size distribution. Ultraviolet (UV) wavelengths (266 nm, $213 \mathrm{~nm}$, and $193 \mathrm{~nm}$ ) are typically used for LA. ${ }^{27}$ The higher photon energy at lower wavelengths allows more energy transfer to the surface during ablation, leading to more mass removal by melting and vaporization. Optical penetration depth is also often greater with UV wavelengths. ${ }^{28}$

\section{Pulse Duration}

Recent strides in the development of LA have involved studies of pulse duration. ${ }^{15-17,}$ ${ }^{24-26}$ Femtosecond lasers have been shown to create a more stoichiometric aerosol overall due to the time scale on which energy is transferred to the sample during the laser pulse. Femtosecond lasers are also reported to generate smaller particles, which leads to less ICPinduced fractionation. Due to the high cost of femtosecond lasers and wide availability of nanosecond lasers, however, LA work continues in both the nanosecond and femtosecond time regimes.

\section{Motion of the Laser Beam}

The motion of the beam during ablation has a dramatic effect on ablation characteristics. When ablation is done on a single spot, there are initially many large 
particles ejected from the surface. As the crater gets deeper, many of the larger particles are deposited on the sides of the crater and do not reach the plasma. In rastering ablation, however, the particle size distribution remains fairly constant as the laser moves across the surface, due to the fact that new, undisturbed surface is constantly being ablated. ${ }^{8}$

\section{Carrier Gas}

Carrier gas, typically He or Ar, plays an important role in the formation of the particle size distribution. ${ }^{23,29}$ Ablation in He generates fewer large particles than ablation in $\mathrm{Ar}$ because energy is dissipated more quickly from the laser-induced plasma in He due to its higher thermal conductivity. ${ }^{30,31}$ The laser-induced plasma at the sample surface is smaller in He and allows for the creation of finer particles by one or a combination of the following two mechanisms. In the first possible mechanism, less incoming radiation is absorbed by the smaller laser-induced plasma. Consequently, more energy is transferred directly to the surface, allowing more of the laser energy to melt and vaporize the sample into smaller particles. ${ }^{32}$ In the second possible mechanism, the particles formed at the surface from the incoming laser beam simply have less time to agglomerate in the smaller plasma. The actual process is likely a combination of these two mechanisms.

Although the composition of the particle size distribution resulting from LA depends on many laser parameters, most recent work has focused on UV lasers in the nanosecond and femtosecond pulse regimes. Laser-induced fractionation due to particle size distributions in LA aerosols is a current research problem with many opportunities for investigation. 


\section{ICP-induced Fractionation}

While fractionation is usually attributed primarily to laser effects, some fractionation is caused by processes in the ICP. ${ }^{8,33}$ Large particles are not completely vaporized, atomized, or ionized in the plasma. When two or more elements are present in a single particle, the most volatile element will vaporize more easily than more refractory elements, leading to ICP-induced fractionation. The effects of ICP-induced fractionation have been isolated from laser-induced fractionation. ${ }^{8}$ Photography and other imaging techniques have been used to study particles in an ICP to gain insight into this problem. ${ }^{13,14,32,34-36}$

\section{Magnetic Sector Mass Spectrometry}

All research involving mass spectrometry in this dissertation was carried out on an Element 1 ICP-MS device. ${ }^{37}$ The Element is a double focusing device in a reverse NierJohnson geometry. After the ion extraction interface and optics to focus the ion beam, a magnetic sector separates ions by their mass to charge ratio $(\mathrm{m} / \mathrm{z})$ followed by an electrostatic analyzer (ESA) for separation by kinetic energy. The result is a very sensitive device with capabilities for high resolution spectra. The typical mode of operation is for the magnet to jump to a particular $\mathrm{m} / \mathrm{z}$ in the general region of interest, where it remains static while the ESA scans the accelerating voltage to deliver a specific $m / z$ to the single detector.

The device has three resolution modes, low $(L R, R=300)$, medium ( $M R, R=4000$ ), and high (HR, $R=10,000)$. In $L R$, the device has peaks similar to those obtained with common quadrupole-based ICP-MS devices. Frequently, polyatomic ions interfere with atomic ions at the same nominal mass in ICP-MS analyses. Sources of these polyatomic ions include common matrix elements such as $\mathrm{Na}, \mathrm{Cl}$, or $\mathrm{K}$ combined with elements present in the 
plasma through solvent introduction or air entrainment such as $\mathrm{Ar}, \mathrm{O}, \mathrm{C}$, and $\mathrm{H}$. For example, ${ }^{40} \mathrm{Ar}^{16} \mathrm{O}^{+}$is an ever-present polyatomic ion that interferes with the most abundant isotope of Fe at $m / 256$ and ${ }^{40} \mathrm{Ar}^{23} \mathrm{Na}^{+}$interferes with ${ }^{63} \mathrm{Cu}^{+}$in a saline matrix. In MR and $\mathrm{HR}$, the magnetic sector ICP-MS device is able to separate most polyatomic interferences from atomic ions at the same nominal mass, overcoming one of the largest fundamental problems in ICP-MS and enabling the determination of most elements even in difficult matrices.

Magnetic sector ICP-MS has many applications, especially where high sensitivity is required or polyatomic interferences otherwise hinder analyses. The technique is currently used in a wide variety of fields, including nuclear nonproliferation, geology, environmental science, forensics, semiconductors, speciation with various separation techniques, and basic research. $^{37-46}$

\section{Dissertation Organization}

The first chapter of this dissertation is a general introduction to ICP-MS, LA, and general applications of magnetic sector mass spectrometry. The ensuing three chapters are each articles published or prepared for submission to scientific journals. Chapter 2 is a paper published in the Journal of Analytical Atomic Spectrometry, which describes an investigation of particle size effects in ICP-MS from aerosols created by nanosecond and femtosecond LA using a magnetic sector ICP-MS device. Chapter 3 is a paper to be submitted to the Journal of Analytical Atomic Spectrometry that describes a high-speed photographic study of single particles from LA and solution nebulization. Chapter 4 is a paper submitted for publication in Analytical and Bioanalytical Chemistry detailing an apparatus for detecting elemental 
release in real time from live neural tissue with a magnetic sector ICP-MS device in MR. Finally, Chapter 5 provides general conclusions and future directions for research.

\section{References}

1. R. S. Houk, V. A. Fassel, G. D. Flesch, H. J. Svec, A. L. Gray and C. E. Taylor, Anal. Chem., 1980, 52, 2283-2289.

2. R. S. Houk and J. J. Thompson, Mass Spectrom. Rev., 1988, 7, 425-461.

3. K. E. Jarvis, A. L. Gray and R. S. Houk, Handbook of Inductively Coupled Plasma Mass Spectrometry, Chapman and Hall, New York. 1992.

4. D. R. Wiederin, F. G. Smith and R. S. Houk, Anal. Chem., 1991, 63, 219-225.

5. A. L. Gray, Analyst, 1985, 110, 551-556.

6. R. E. Russo, X. Mao and O. V. Borisov, Trends. Anal. Chem., 1998, 17, 461-469.

7. S. F. Durrant, J. Anal. At. Spectrom., 1999, 14, 1385-1403.

8. M. Guillong and D. Günther, J. Anal. At. Spectrom., 2002, 17, 831-837.

9. H. R. Kuhn, M. Guillong and D. Günther, Anal. Bioanal. Chem., 2003, 378, 10691074.

10. R. E. Russo, X. L. Mao and S. S. Mao, Anal. Chem., 2002, 74, 71A-77A.

11. M. Guillong, H. R. Kuhn and D. Günther, Spectrochim. Acta, Part B, 2003, 58B, 211220.

12. S. H. Jeong, O. V. Borisov, J. H. Yoo, X. L. Mao and R. E. Russo, Anal. Chem., $1999,71,5123-5130$.

13. J. W. Olesik, Appl Spectrosc, 1997, 51, 607-616.

14. J. W. Olesik, Appl Spectrosc, 1997, 51, 158A-175A. 
15. N. J. Saetveit, S. J. Bajic, D. P. Baldwin and R. S. Houk, J. Anal. At. Spectrom., 2008, 23, 54-61.

16. D. C. Perdian, S. J. Bajic, D. P. Baldwin and R. S. Houk, J. Anal. At. Spectrom., $2008,23,325-335$.

17. D. C. Perdian, S. J. Bajic, D. P. Baldwin and R. S. Houk, J. Anal. At. Spectrom., $2008,23,336-341$.

18. R. Hergenröder, J. Anal. At. Spectrom., 2006, 21, 1016-1026.

19. J. Koch, H. Lindner, A. von Bohlen, R. Hergenröder and K. Niemax, J. Anal. At. Spectrom., 2005, 20, 901-906.

20. H. R. Kuhn, M. Guillong and D. Günther, Anal. Bioanal. Chem., 2004, 378, 1069 1074.

21. J. Koch, A. v. Bohlen, R. Hergenroder and K. Niemax, J. Anal. At. Spectrom., 2004, $19,267-272$.

22. H. R. Kuhn and D. Günther, Anal. Chem., 2003, 75, 747-753.

23. I. Horn and D. Günther, Appl. Surf. Sci., 2003, 207, 144-157.

24. C. C. Garcia, H. Lindner, A. v. Bohlen, C. Vadla and K. Niemax, J. Anal. At. Spectrom., 2008, 23, 470-478.

25. J. J. Gonzalez, D. Oropeza, X. Mao and R. E. Russo, J. Anal. At. Spectrom., 2008, 23, 229-234.

26. J. Koch, M. Walle, J. Pisonero and D. Günther, J. Anal. At. Spectrom., 2006, 21, $932-$ 940.

27. M. Guillong, I. Horn and D. Günther, J. Anal. At. Spectrom., 2003, 18, 1224-1230. 
28. J. Gonzales, X. L. Mao, J. Roy, S. S. Mao and R. E. Russo, J. Anal. At. Spectrom., $2002,17,1108-1113$.

29. I. I. Stewart, C. E. Hensman and J. W. Olesik, Appl Spectrosc, 2000, 54, 164-174.

30. S. M. Eggins, L. P. Kinsley and J. M. G. Shelley, Appl. Surf. Sci., 1998, 127-129, $278-286$.

31. D. Günther and C. A. Heinrich, J. Anal. At. Spectrom., 1999, 14, 1363-1368.

32. D. B. Aeschliman, S. J. Bajic, D. P. Baldwin and R. S. Houk, J. Anal. At. Spectrom., $2003,18,1008-1014$

33. I. Kroslakova and D. Günther, J. Anal. At. Spectrom., 2007, 22, 51-62.

34. R. S. Houk, R. K. Winge and X. Chen, J. Anal. At. Spectrom., 1997, 12, 1139.

35. R. K. Winge, J. S. Crain and R. S. Houk, J. Anal. At. Spectrom., 1991, 6, 601.

36. M. T. Cicerone and P. B. Farnsworth, in Spectrochim. Acta, Part B. 1989, vol. 44, p. 897.

37. R. S. Houk, in Handbook of Elemental Speciation, ed. R. Cornelius, J. Caruso, H. Crews and K. Heumann, John Wiley \& Sons. 2002.

38. J. i. J. Gonzalez, D. Oropeza, X. Mao and R. E. Russo, J. Anal. At. Spectrom., 2008, 23, 229-234.

39. F. Pointurier, P. Hémet and A. Hubert, J. Anal. At. Spectrom., 2008, 23, 94-102.

40. K. C. Sears, J. W. Ferguson, T. J. Dudley, R. S. Houk and M. S. Gordon, J. Phys. Chem. A, 2008, 112, 2610-2617.

41. J. W. Ferguson and R. S. Houk, Spectrochim. Acta, Part B, 2006, 61, 905-915.

42. S. J. Bajic, D. B. Aeschliman, N. J. Saetveit, D. P. Baldwin and R. S. Houk, J. Forensic Sci., 2005, 50, 1123-1127. 
43. C. J. Choi, V. Anantharam, N. J. Saetveit, R. S. Houk, A. Kanthasamy and A. G.

Kanthasamy, Toxicol. Sci., 2007, 98, 495-509.

44. M. Leermakers, W. Baeyens, M. De Gieter, B. Smedts, C. Meert, H. C. De Bisschop, R. Morabito and P. Quevauviller, Trends. Anal. Chem., 2006, 25, 1-10.

45. Y. Takaku, K. Masuda, T. Takahashi and T. Shimamura, J. Anal. At. Spectrom., 1994, 9, 1385-1387.

46. F. Poitrasson and R. Freydier, Chem. Geol., 2005, 222, 132-147. 


\title{
Chapter 2. Influence of particle size on fractionation with nanosecond and femtosecond laser ablation in brass by online differential mobility analysis and inductively coupled plasma mass spectrometry
}

A paper published in the Journal of Analytical Atomic Spectrometry

Nathan J. Saetveit, Stanley J. Bajic, David P. Baldwin, and R. S. Houk

\begin{abstract}
A differential mobility analyzer (DMA) passes laser ablation (LA) particles and agglomerates within a narrow range of electrical mobilities to the inductively coupled plasma mass spectrometer (ICP-MS). No particle collection or offline particle analysis is required. Fractionation is assessed with the $\mathrm{Cu}^{+} / \mathrm{Zn}^{+}$signal ratio. Results presented in this paper support previous findings that ns LA provides many small $\mathrm{Zn}$-rich particles and some much larger $\mathrm{Cu}-$-rich particles and that fs LA produces large agglomerates of small particles. The composition of the aerosol produced by fs LA falls between the relatively $\mathrm{Zn}$-rich and $\mathrm{Cu}$ rich extremes of ns LA. Femtosecond LA provides elemental ratio measurements that remain more stable with respect to time, which allows a greater degree of confidence in LA results. Even though some parameters besides pulse length differ between the lasers compared in this study, the suppression of particle size related fractionation with fs LA can be attributed to pulse length.
\end{abstract}

\section{Introduction}

LA-ICP-MS is an appealing technique for the fast, sensitive, and spatially resolved trace elemental analysis of a wide variety of solids. ${ }^{1-3}$ However, elemental fractionation 
remains a problem for the technique, especially for ns LA. ${ }^{4-7}$ Elemental fractionation in LA has been used to describe the changes in elemental ratios as a function of various experimental parameters. Unfortunately, the same term has come to refer to different effects. One common definition of fractionation describes the time-dependent change of elemental ratios during a single LA run; this phenomenon is only briefly addressed in this work. The term fractionation can also refer to deviations between the overall determined elemental ratio and the actual stoichiometry of the sample, with no regard for time-dependent changes. This work primarily examines fractionation as the change in elemental ratio as a function of particle size.

Many causes of fractionation have been investigated in the different stages of LAICP-MS, and various methods have been explored to compensate for, reduce, or eliminate fractionation. Fractionation due to the LA process is affected by many laser parameters, including wavelength, ${ }^{8-12}$ energy density, ${ }^{12-15}$ and pulse duration, ${ }^{11,16-21}$ which can affect the size distribution and composition of the aerosol. Fractionation has also been attributed to transport and ICP effects, which are also affected by particle size. ${ }^{22-29}$ Smaller particles generally lead to less ICP-induced fractionation. Still, thermal effects of the LA process, such as melting, differential vaporization among elements, and re-ablation of deposited particles, can cause fractionation even if large particles are not transported effectively to the plasma or are filtered from the aerosol before reaching the ICP. Relative to ns lasers, fs lasers have been reported to reduce or eliminate these thermal effects, providing both a more nearly stoichiometric aerosol and smaller particles with a narrower size distribution. ${ }^{5,16}$

To investigate particles resulting from LA, techniques such as optical particle sizing, particle impaction, and differential mobility analysis have been demonstrated. ${ }^{30-31}$ Optical 
particle sizing can determine size distributions of LA aerosols, but it cannot transmit a selected range of particle size for direct, online analysis with ICP-MS. Particle impaction can be used to analyze and measure a wide range of particle and agglomerate sizes and shapes and can be used as a low pass size filter for online analysis. However, to analyze a particle size range defined by both a low and a high cutoff, the technique is limited to offline analysis, which is tedious and time-consuming. Only differential mobility analysis offers the flexibility to directly select and examine particles and agglomerates in a specific electric mobility diameter range during online elemental analysis by ICP-MS.

In this work, particles of a range of sizes are produced during LA, and a range of particles and agglomerates centered around a desired electrical mobility diameter $\left(d_{m}\right)$ is selected by a DMA and passed directly to the ICP-MS for elemental analysis. As noted elsewhere, ${ }^{31} d_{m}$ is not equivalent to particle volume or mass since the structure of the particle or agglomerate contributes to its electrical mobility. Therefore, particles are inseparable from agglomerates at each $d_{m}$ value of the DMA. Still, the DMA provides valuable insights into particle size effects on fractionation because it allows direct, online selection and variation of specific electrical mobility fractions of the total LA aerosol. While not the primary focus of this work, the time stability of elemental ratio measurements during rastering and single spot LA is also briefly investigated.

Due to their different volatilities, $\mathrm{Cu}$ and $\mathrm{Zn}$ in brass were chosen as the primary elements to examine particle size and laser effects on fractionation. Obtaining the "true" $\mathrm{Cu}^{+} / \mathrm{Zn}^{+}$ratio is not the focus of this work. Since the experimentally determined $\mathrm{Cu}^{+} / \mathrm{Zn}^{+}$ ratio may be dependent on factors such as sampling position, ionization efficiency, differential atomization, and mass bias, this work is mainly concerned with changes or trends 
in the $\mathrm{Cu}^{+} / \mathrm{Zn}^{+}$signal ratio with $d_{m}$. Any observed change in elemental signal ratio with respect to $d_{m}$ is evidence of particle size related fractionation at some $d_{m}$. Otherwise, the same $\mathrm{Cu}^{+} / \mathrm{Zn}^{+}$signal ratio would be obtained at all $d_{m}$ values.

\section{Experimental}

\section{Laser Ablation}

A CETAC Technologies LSX-500 LA system was used for ns LA. The laser is a Qswitched, beam-homogenized, frequency-quadrupled $(266 \mathrm{~nm}) \mathrm{Nd}$ :YAG laser. The sample is placed on a movable $x y z$-translation stage, and ablation can be visually monitored in real time with a charge-coupled device (CCD) and a zoom lens. A pulse width of $<6 \mathrm{~ns}$, repetition rate of $10 \mathrm{~Hz}$, spot size of $100 \mu \mathrm{m}$, and energy specified to be $\sim 9 \mathrm{~mJ}$ per pulse were used.

A Fiber Chirped Pulse Amplification (FCPA) fs laser was used for fs LA (FCPA. $\mu$ Jewel, IMRA America, Inc., Ann Arbor, MI, USA). This laser provides pulses of approximately $3.7 \mu \mathrm{J}$ and $370 \mathrm{fs}$ at a wavelength of $1045 \mathrm{~nm}$ and a repetition rate of 100 $\mathrm{kHz}$. The spot size was determined by the focus of the laser; after the experiments it was measured to be approximately $50 \mu \mathrm{m}$. The samples were placed in a homemade ablation cell, mounted on an $x y z$-translation stage, and viewed with a CCD camera.

Both lasers used cylindrical ablation cells with the gas entering the ablation region at the bottom and exiting at the top. For the ns laser, the standard ablation cell from CETAC was used: $25 \mathrm{~mm}$ high $\times 60 \mathrm{~mm}$ diam., total volume $70 \mathrm{~cm}^{3}$, inlet $2 \mathrm{~mm}$ ID. For the fs laser, a homemade, double-walled cell was used: $45 \mathrm{~mm}$ high $\times 50 \mathrm{~mm}$ diam., total volume 90 $\mathrm{cm} 3$, inlet $4 \mathrm{~mm}$ ID. The same Tygon tubing ( $4 \mathrm{~mm} \mathrm{ID} \mathrm{x} \sim 1 \mathrm{~m} \mathrm{long}$ ) was used to conduct 
the aerosol to the ICP in both cases. The same brass sample was ablated with the ns laser using either cell; the signal levels and noise behavior were similar. Thus, the cell geometry does not greatly affect the signal or noise behavior described below.

\section{Differential Mobility Analyzer}

An electrostatic classifier using a DMA (Model 3080L, TSI Inc., Shoreview, MN, USA) selectively passed ablated particleș and agglomerates centered around a specific $d_{m}{ }^{30,32}$ to the ICP-MS device. ${ }^{31}$

\section{ICP-MS}

A Finnigan Element 1 ICP-MS device was used. ${ }^{33-35}$ This device consists of a magnetic sector and electrostatic analyzer in a reverse Nier-Johnson arrangement. Low resolution mode $(\mathrm{m} / \Delta \mathrm{m}=300)$ was used throughout these experiments since higher resolution was not necessary for the isotopes observed.

\section{Samples and Conditions}

NIST brass standards $\mathrm{Cl} 100$ and $\mathrm{C} 1102$ were analyzed. Table 1 summarizes the ICPMS operating conditions and the isotopes measured. Argon was used as a carrier gas, and sample gas flow rate was optimized in each experiment for maximum ICP-MS signal stability. This flow rate is approximately $0.15 \mathrm{~L} / \mathrm{min}$ lower than that which provides maximum mass transport from the ablation cell and sacrifices approximately one order of magnitude of signal. However, this lower sample gas flow rate leads to far more stable LA 
signal response from the ICP-MS device. Experiments were done in rastering and single spot modes on both samples. No sample pretreatment was performed.

For the rastering experiments, the samples were moved under the stationary laser beam at approximately $30 \mu \mathrm{m} / \mathrm{s}$. Rastering times of 171 and 341 seconds (100 and 200 ICPMS scans) were used for the ns and fs experiments, respectively.

For the ns single spot ablation experiments, a spot was continuously ablated at $10 \mathrm{~Hz}$ for approximately 120 seconds (70 ICP-MS scans through the mass range). For the fs single spot experiments, the laser very quickly drilled into the surface deep enough to be out of focus and below the ablation threshold. Therefore, limited signal was obtained for the fs single spot ablation experiments.

For each set of experiments (rastering and single spot ablation with both lasers on the samples, for a total of eight sets of experiments), data were acquired with the DMA for particles with a $d_{m}$ ranging from $50 \mathrm{~nm}$ to $1000 \mathrm{~nm}$, in $25-\mathrm{nm}$ increments. For the fs experiments, data acquired at $d_{m}=100 \mathrm{~nm}$ and below were not included in the final plots because of low signal level. The sample gas flow was kept constant within each experiment so that changes in measured signals would only be attributable to $d_{m}$.

Due to the high voltage applied to the electrodes in the DMA, arcing can be a problem when using Ar as a carrier gas. Under the conditions of these experiments, an abrupt signal change, likely caused by arcing, was sometimes observed at $d_{m}>1000 \mathrm{~nm}$. In two experiments, single spot fs LA on NIST C1100 and rastering ns LA on NIST C1102, arcing may have been responsible for some artifacts at $d_{m}<1000 \mathrm{~nm}$ (data not shown in figures). The data trends prior to the possible arcing are consistent with those in the other experiments. Since the trends were consistent between samples and for brevity, only the figures describing 
the results from one standard are presented for each laser (ns, NIST C1100; fs, NIST C1102). All data, including those not presented in the figures, are included in the summary in Table 2.

\section{Data Analysis}

Three types of plots were generated from the raw ICP-MS data. First, the data were background subtracted, and the peaks from each isotope were integrated for each ICP-MS scan. Integrated count rates from two isotopes each of $\mathrm{Cu}$ and $\mathrm{Zn}$ were summed and normalized to $100 \%$ of the respective element. Plots of normalized signal count rate vs. $d_{m}$, elemental ratio vs. $d_{m}$, and a 3-dimensional plot of elemental ratio vs. $d_{m}$ vs. time were generated for each pair of elements and for each experiment. For the single spot ablation experiments, the signals from each spot were integrated for the duration of the experiment. No standard deviations are reported for the single spot ablation experiments because each reported count rate is the integrated signal from a single spot.

\section{Results and Discussion}

\section{System Noise Analysis from Isotope Ratios}

To characterize any experimental or data analysis artifacts in the data plots, plots of ${ }^{63} \mathrm{Cu}^{+} /{ }^{65} \mathrm{Cu}^{+}$and ${ }^{64} \mathrm{Zn}^{+} /{ }^{66} \mathrm{Zn}^{+}$signal ratios were prepared for each experiment. (Figs. 1 and 2 ). No upward or downward trends in these intraelemental ratios are observed with respect to $d_{m}$, with the possible exception of single spot ablation with the fs laser at very small $d_{m}$, which is attributable to the low signal level discussed previously. These data help confirm that any trends observed in the $\mathrm{Cu}^{+} / \mathrm{Zn}^{+}$signal ratio with respect to $d_{m}$ are due to particle size related elemental fractionation and not experimental or analysis artifacts. 


\section{Nanosecond LA}

Fig. 3 shows the $\mathrm{Cu}^{+} / \mathrm{Zn}^{+}$signal ratio plots for rastering and single spot ns LA of NIST $\mathrm{C} 1100$ brass. Both rastering and single spot ablation show similar trends with respect to $d_{m}$. The $\mathrm{Cu}^{+} / \mathrm{Zn}^{+}$signal ratio steadily increases with $d_{m}$ at values between approximately $300 \mathrm{~nm}$ to $600 \mathrm{~nm}$, which supports previous observations by Niemax et al. ${ }^{14}$ and Russo et al. $^{25}$

The signal plots shown in Fig. 4 show a maximum in signal for both $\mathrm{Cu}^{+}$and $\mathrm{Zn}^{+}$ centered at $d_{m}=200 \mathrm{~nm}$. The transfer function of the DMA, which is related to the width of the $d_{m}$ transmission window, increases with $d_{m},{ }^{31,32}$ which would bias the signal toward large $d_{m}$. In addition, larger particles contain more analyte atoms. Since the plots show the largest signal count rate for smaller $d_{m}$ values, from $100 \mathrm{~nm}$ to $300 \mathrm{~nm}$, more particles and/or agglomerates are produced in this range than at larger $d_{m}$ values. These findings are consistent with previous work. , $^{44,25}$

While the DMA cannot directly provide information about the nature of the particles being passed (i.e., whether they are single particles or agglomerates of smaller particles), some such information can be gleaned from the ICP-MS signal itself. There is a dramatic increase in the relative standard deviation of the ICP-MS signal with $d_{m}$ during the rastering experiment ( $4 \%$ for $d_{m} \leq 200 \mathrm{~nm}$ to $18 \%$ for $d_{n} \geq 600 \mathrm{~nm}$ ), beginning at $d_{m} \sim 400 \mathrm{~nm}$ (Fig. 4). This noise is likely caused by larger, single particles that are less completely vaporized, atomized, and ionized in the plasma causing localized pockets of excess ions. ${ }^{36}$ At smaller particle sizes, all the particles and agglomerates are more extensively vaporized, atomized, and ionized, leading to a much more stable and less noisy ICP-MS signal. ${ }^{22}$ It is still likely, though, that agglomerates of smaller particles exist at all $d_{m}$ values included in this study. ${ }^{37}$ 


\section{Femtosecond LA}

Fig. 5 shows plots from rastering and single spot fs LA of NIST C1102 brass. In these experiments, there was some variation of elemental ratios with $d_{m}$, but the aerosol had more uniform $\mathrm{Cu}^{+} / \mathrm{Zn}^{+}$signal ratio (a smaller difference between low $d_{m}$ and high $d_{m}$ ) throughout the entire $d_{m}$ range than aerosol from ns LA. Contrary to the trend observed in the ns LA experiments, the $\mathrm{Cu}^{+} / \mathrm{Zn}^{+}$signal ratio decreased slightly with higher $d_{m}$ values in the fs LA experiments.

The curves in Fig. 6 show that the majority of the ICP-MS signal comes from particles and agglomerates with $d_{m}>200 \mathrm{~nm}$. Previous work ${ }^{14,17}$ has shown that fs LA of brass produces an aerosol composed of agglomerates of very small particles. The current study supports this previous work: Since most of the signal is found at higher $d_{m}$ values, the aerosol is composed of either a distribution of large particles or large agglomerates of small particles. However, the small relative standard deviations observed in the signal and ratio plots imply that there is not a distribution of large particles causing excessive ICP-MS signal fluctuation, but rather a size distribution of agglomerates composed of similar-sized, small particles. ${ }^{14,17}$

As described elsewhere, ${ }^{14,38,39}$ the particle re-condensation model describes a likely mechanism for production of these small particles. Since $\mathrm{Zn}$ is more volatile than $\mathrm{Cu}$ and would nucleate later in a saturated vapor, it is reasonable that the smallest condensed particles are relatively $\mathrm{Zn}$-rich compared to the slightly larger condensed particles. Since smaller particles tend to agglomerate more readily than larger particles, ${ }^{17}$ it is expected that larger agglomerates would tend to be slightly $\mathrm{Zn}$-rich, relative to smaller agglomerates. 
Assuming the particle re-condensation model as the dominant particle formation mechanism, this qualitative explanation is consistent with the $\mathrm{Cu}^{+} / \mathrm{Zn}^{+}$signal ratios shown in Fig. 5a. Different $\mathrm{Cu}^{+} / \mathrm{Zn}^{+}$signal ratios in particles of different sizes formed during fs $\mathrm{LA}$ are expected, ${ }^{14}$ but the overall $\mathrm{Cu}^{+} / \mathrm{Zn}^{+}$signal ratio is still much more uniform throughout the $d_{m}$ range in fs LA than in ns LA.

\section{Plasma Loading Effects}

Mass loading in the ICP has recently been reported to have a large effect on experimental ratios in LA-ICP-MS of silicates under certain conditions. ${ }^{7,11}$ However, the magnitude of this effect in LA analyses of brass has not been fully investigated. For silicate matrices, this mass loading effect causes the $\mathrm{Cu}^{+} / \mathrm{Zn}^{+}$signal ratio to increase with increased mass loading; signal from $\mathrm{Zn}$, which is more difficult to ionize than $\mathrm{Cu}$, would be more suppressed than that from $\mathrm{Cu}$ due to the cooling of the plasma by higher mass loading. ${ }^{11}$ The matrix of the brass standards used in this study is well over $99 \% \mathrm{Cu}$ and $\mathrm{Zn}$, but typical silicates have only a small fraction of these elements. It is unclear whether the mass loading effect observed during LA of silicates would be present when the sample is composed of almost $100 \%$ of the analytes of interest. It is prudent, however, to assume that there may be some mass loading effect on the $\mathrm{Cu}^{+} / \mathrm{Zn}^{+}$signal ratio in LA of brass. If mass loading had a dominant effect on the $\mathrm{Cu}^{+} / \mathrm{Zn}^{+}$signal ratios in these experiments, the $\mathrm{Cu}^{+} / \mathrm{Zn}^{+}$signal ratios would trend in the same direction as the signal intensity with changes in $d_{m}$. This is not observed. Although mass loading effects may be present in these experiments, the observed effects are more consistent with particle size related fractionation due to differences in the LA aerosols. 


\section{Comparison of Trends}

Table 2 summarizes trends in the $\mathrm{Cu}^{+} / \mathrm{Zn}^{+}$signal ratio (weighted by the $\mathrm{Cu}^{+}$signal) and signal levels in different $d_{m}$ regimes for the eight sets of experiments. Data are included for all samples and conditions, including those not shown in other plots. The weighting by $\mathrm{Cu}^{+}$signal relates the data to contributions by each $d_{m}$ size regime to the overall $\mathrm{Cu}^{+} / \mathrm{Zn}^{+}$ signal ratio that would be measured using these lasers and conditions without the DMA.

Different trends in the $\mathrm{Cu}^{+} / \mathrm{Zn}^{+}$signal ratio and signals with respect to $d_{m}$ are evident between ns and fs LA. Nanosecond LA aerosols in all experiments show a substantial increase in the $\mathrm{Cu}^{+} / \mathrm{Zn}^{+}$signal ratio in larger $d_{m}$ regimes, while aerosols in the fs LA experiments show a gradual decrease in the $\mathrm{Cu}^{+} / \mathrm{Zn}^{+}$signal ratio in larger $d_{m}$ regimes. In the ns LA experiments, even the least pronounced ratio difference between the lowest and highest $d_{m}$ regimes (single spot, NIST C1100) is larger than that in any of the fs LA experiments. In addition, the $\mathrm{Cu}^{+} / \mathrm{Zn}^{+}$signal ratios for fs LA in all $d_{m}$ regimes fall between the $\mathrm{Zn}$-rich and $\mathrm{Cu}$-rich extremes of ns LA. This is not immediately clear for the case of ns single spot LA on $\mathrm{C} 1100$; the rise of the $\mathrm{Cu}^{+} / \mathrm{Zn}^{+}$signal ratio is found at higher $d_{m}$ than in other experiments (Fig. 3), which skews the average in the $d_{m} \geq 600 \mathrm{~nm}$ regime to a somewhat lower value (maximum $\mathrm{Cu}^{+} / \mathrm{Zn}^{+}$signal ratio, 7.03). Another trend observed is that the percentage of total signal obtained with ns LA was generally higher in lower $d_{m}$ regimes, while the opposite was normally true for fs experiments.

These trends, which are independent of sample and sampling style, along with the previous discussion regarding the differences in relative standard deviations of the ICP-MS signals or ratios, reinforce the predominant view that ns LA produces many small particles 
$\left(d_{m}<300 \mathrm{~nm}\right)$ and some large, single, Cu-rich particles, while fs aerosols are predominantly agglomerates of small particles.

Since this work assesses particle size related fractionation through trends in the $\mathrm{Cu}^{+} / \mathrm{Zn}^{+}$signal ratio with $d_{m}$, obtaining the "true" $\mathrm{Cu}^{+} / \mathrm{Zn}^{+}$value is not required. While an in depth study of the overall stoichiometry of the LA aerosols would obfuscate the purpose of this paper as a fast, online, qualitative assessment of particle size related fractionation in readily available ns and fs lasers, it is still of some interest to assess the stoichiometry of the LA aerosols. To that end, the ratio of the $\mathrm{Cu}^{+} / \mathrm{Zn}^{+}$signal ratios in the two standards was calculated $\left[\mathrm{Cu}^{+} / \mathrm{Zn}^{+}{ }_{(\mathrm{Cl102})} / \mathrm{Cu}^{+} / \mathrm{Zn}^{+}{ }_{(\mathrm{Cl} 100)}\right]$ for all of the experiments to assess this type of fractionation. In the absence of fractionation, the true ratio, 1.284, would be expected. Table 3 shows a summary of this ratio determined for three $d_{m}$ regimes and for the overall aerosol. There is some deviation from the true value in the various $d_{m}$ regimes for experiments with both lasers, but the largest particles from ns LA demonstrate the highest degree of fractionation. Femtosecond LA gives an overall more stoichiometric aerosol than ns LA for both single spot and rastering LA. This method of looking at the overall stoichiometry of LA aerosols is not intended to be a comprehensive analysis, but rather a rudimentary assessment, of overall fractionation.

\section{Time Stability}

Three-dimensional plots of elemental ratio vs. $d_{m}$ vs. time were made to assess time dependence on elemental ratio measurements while using rastering or single spot LA. Fig. 7 shows that for both rastering and single spot ns LA, the $\mathrm{Cu}^{+} / \mathrm{Zn}^{+}$signal ratio is stable at small $d_{m}$ values but fluctuates wildly at large $d_{m}$ values. Fig. 8 demonstrates that rastering with the 
fs laser provides more stable elemental ratio measurements with respect to time for all $d_{m}$ compared to ns rastering LA. The spikes at small $d_{m}$ values are largely due to counting statistics at the low signal level. Since there was a very short signal transient when using single spot ablation with the fs laser, this type of elemental ratio vs. $d_{m}$ vs. time plot is not informative for those data.

\section{Conclusions}

The fast, online measurement of elemental compositions of selected aerosol sizes in this study demonstrates a feasible qualitative complement to time-consuming offline studies involving other particle analysis techniques. The $\mathrm{Cu}^{+} / \mathrm{Zn}^{+}$signal ratios obtained throughout the $d_{m}$ range from both single spot and rastering fs LA fall between the ratios found from the relatively $\mathrm{Zn}$-rich and $\mathrm{Cu}$-rich extremes in the ns LA experiments. Aerosols from fs LA provide much more stable elemental ratios with respect to $d_{m}$ and time, which allows greater confidence in fs LA results.

The two lasers were operated in their "out-of-the-box" state to compare ns and fs LA with readily available laser systems. The two lasers used in this study have obvious differences, including wavelength, repetition rate, and pulse duration, and these parameters could not be matched for the two systems. However, many of the parameters that differ between these two lasers, with the notable exception of pulse duration, would be expected to enhance particle size related fractionation for the fs laser, especially the longer wavelength and faster repetition rate. Since the fs laser suppressed particle size related fractionation, it is reasonable, based on previous research, ${ }^{5,14,16,17,25}$ to attribute this suppression largely to the much shorter pulse length. 
Future studies will include more in depth examination of the sub-100 nm regime for both rastering and single spot fs LA to gain further insight into the elemental composition of the particles throughout this particle size range. Other results using fast data acquisition are currently in preparation. ${ }^{40-41}$.

\section{Acknowledgements}

TSI, Inc., Shoreview, MN, USA, provided the electrostatic classifier/DMA. IMRA America, Inc., Ann Arbor, MI, USA, provided the FCPA $\mu$ Jewel fs laser. Ames Laboratory is operated for the U. S. Department of Energy (USDOE) by Iowa State University of Science and Technology under Contract No. DE-AC02-07CH11358. This work was

supported by the USDOE, Office of Defense Nuclear Nonproliferation, Office of Nonproliferation Research and Engineering, NA-22.

\section{References}

1. A. L. Gray, Analyst, 1985, 110, 551-556.

2. R. E. Russo, X. Mao and O. V. Borisov, Trends Anal. Chem., 1998, 17, 461-469.

3. S. F. Durrant, J. Anal. At. Spectrom., 1999, 14, 1385-1403.

4. H. R. Kuhn and D. Günther, Anal. Chem., 2003, 75, 747-753.

5. J. Koch, H. Lindner, A. von Bohlen, R. Hergenröder and K. Niemax, J. Anal. At. Spectrom., 2005, 20,901-906.

6. M. Guillong and D. Günther, J. Anal. At. Spectrom., 2002, 17, 831-837.

7. I. Kroslakova and D. Günther, J. Anal. At. Spectrom., 2007, 1, 51-62. 
8. R. E. Russo, X. L. Mao, O. V. Borisov and H. Liu, J. Anal. At. Spectrom., 2000, 9, $1115-1120$.

9. M. Guillong, I. Horn and D. Günther, J. Anal. At. Spectrom., 2003, 10, 1224-1230.

10. J. Gonzáles, C. Liu, X. Mao, R. E. Russo, J. Anal. At. Spectrom., 2004, 9, 1165-1168.

11. J. Koch, M. Wälle, J. Pisonero and D. Günther, J. Anal. At. Spectrom., 2006, 9, 932940.

12. T. Iizuka and T. Hirata, Geochem. J., 2004, 38, 229-241.

13. J. H. Yoo, O. V. Borisov, X. Mao and R. E. Russo, Anal. Chem., 2001, 73, 22882293.

14. J. Koch, A. von Bohlen, R. Hergenröder and K. Niemax, J. Anal. At. Spectrom., 2004, $19,267-272$.

15. S. H. Jeong, O. V. Borisov, J. H. Yoo, X. L. Mao and R. E. Russo, Anal. Chem., $1999,71,5123-5130$.

16. R. E. Russo, X. Mao, J. J. González and S. S. Mao, J. Anal. At. Spectrom., 2002, 17, 1072-1075.

17. C. Liu, X. L. Mao, S. S. Mao, X. Zeng, R. Greif and R. E. Russo, Anal. Chem. 2004, $76,379-383$.

18. J. González, S. H. Dundas, C. Y. Liu, X. Mao and R. E. Russo, J. Anal. At. Spectrom., $2006,8,778-784$.

19. Q. Bian, C. C. Garcia, J. Koch and K. Niemax, J. Anal. At. Spectrom., 2006, 2, $187-$ 191.

20. J. Koch and D. Günther, Anal. Bioanal. Chem., 2007, 387, 149-153. 
21. F. Poitrasson, X. Mao, S. S. Mao, R. Freydier and R. E. Russo, Anal. Chem. 2003, 75, $6184-6190$.

22. D. B. Aeschliman, S. J. Bajic, D. P. Baldwin and R. S. Houk, J. Anal. At. Spectrom., $2003,9,1008-1014$

23. C. Y. Liu, X. L. Mao, J. González and R. E. Russo, J. Anal. At. Spectrom., 2005, 20, 200-203.

24. H. R. Kuhn and D. Günther, J. Anal. At. Spectrom., 2004, 19, 1158-1164.

25. C. Liu, X. Mao, S. S. Mao, R. Greif and R. E. Russo, Anal. Chem., 2005, 77, 66876691.

26. B. Hattendorf, C. Latkoczy and D. Günther, Anal. Chem., 2003, 75, 341A-347A.

27. H. R. Kuhn, M. Guillong and D. Günther, Anal. Bioanal. Chem., 2004, 378, 10691074.

28. L. Yang, R. E. Sturgeon and Z. Mester, Anal. Chem. 2005, 77, 2971-2977.

29. D. Bleiner, P. Lienemann and H. Vonmont, Talanta, 2005, 65, 1286-1294.

30. E. O. Knutson and K. T. Whitby, J. Aerosol Sci., 1975, 6, 443-451.

31. H. R. Kuhn, J. Koch, R. Hergenröder, K. Niemax, M. Kalberer and D. Günther, J. Anal. At. Spectrom., 2005, 20, 894-900.

32. C. Hagwood, Y. Sivathanu and G. Mulholland, Aerosol Sci. Technol. 1999, 30, 40-61.

33. R. S. Houk, V. A. Fassel, G. D. Flesch, H. J. Svec, A. L. Gray and C. E. Taylor, Anal. Chem., 1980, 52, 2283-2289.

34. L. Moens and N. Jakubowski, Anal. Chem., 1998,70, 251A-256A. 
35. R. S. Houk, Elemental Speciation by ICP-MS with High Resolution Instruments, in Handbook of Elemental Speciation, R. Cornelis, J. Caruso, H. Crews and K. Heumann, eds., John Wiley \& Sons, 2002.

36. D. C. Perdian and R. S. Houk, unpublished work.

37. H. R. Kuhn and D. Günther, Anal. Bioanal. Chem., 2005, 383, 434-441.

38. B. S. Luk'yanchuk, W. Marine and S. I. Anisimov, Laser Phys., 1998, 8, 291-302.

39. R. Hergenröder, J. Anal. At. Spectrom., 2006, 10, 1016-1026.

40. D. C. Perdian, S. J. Bajic, D. P. Baldwin and R. S. Houk, J. Anal. At. Spectrom., $2008,23,325-335$.

41. D. C. Perdian, S. J. Bajic, D. P. Baldwin and R. S. Houk, J. Anal. At. Spectrom., $2008,23,326-341$. 
Table 1. ICP-MS Operating Conditions

ICP-MS device

Outer gas

Auxiliary gas

Sample gas

Forward Rf power

Detector mode

Mass window

Sampling time

Samples per peak

Isotopes measured
Finnigan Element 1

$14 \mathrm{~L} / \mathrm{min}$

$0.70-0.75 \mathrm{~L} / \mathrm{min}$

$1.05-1.10 \mathrm{~L} / \mathrm{min}$

$1200 \mathrm{~W}$

Analog

$150 \%$

$0.01 \mathrm{~s}$

10

${ }^{63} \mathrm{Cu},{ }^{64} \mathrm{Zn},{ }^{65} \mathrm{Cu},{ }^{66} \mathrm{Zn}$ 


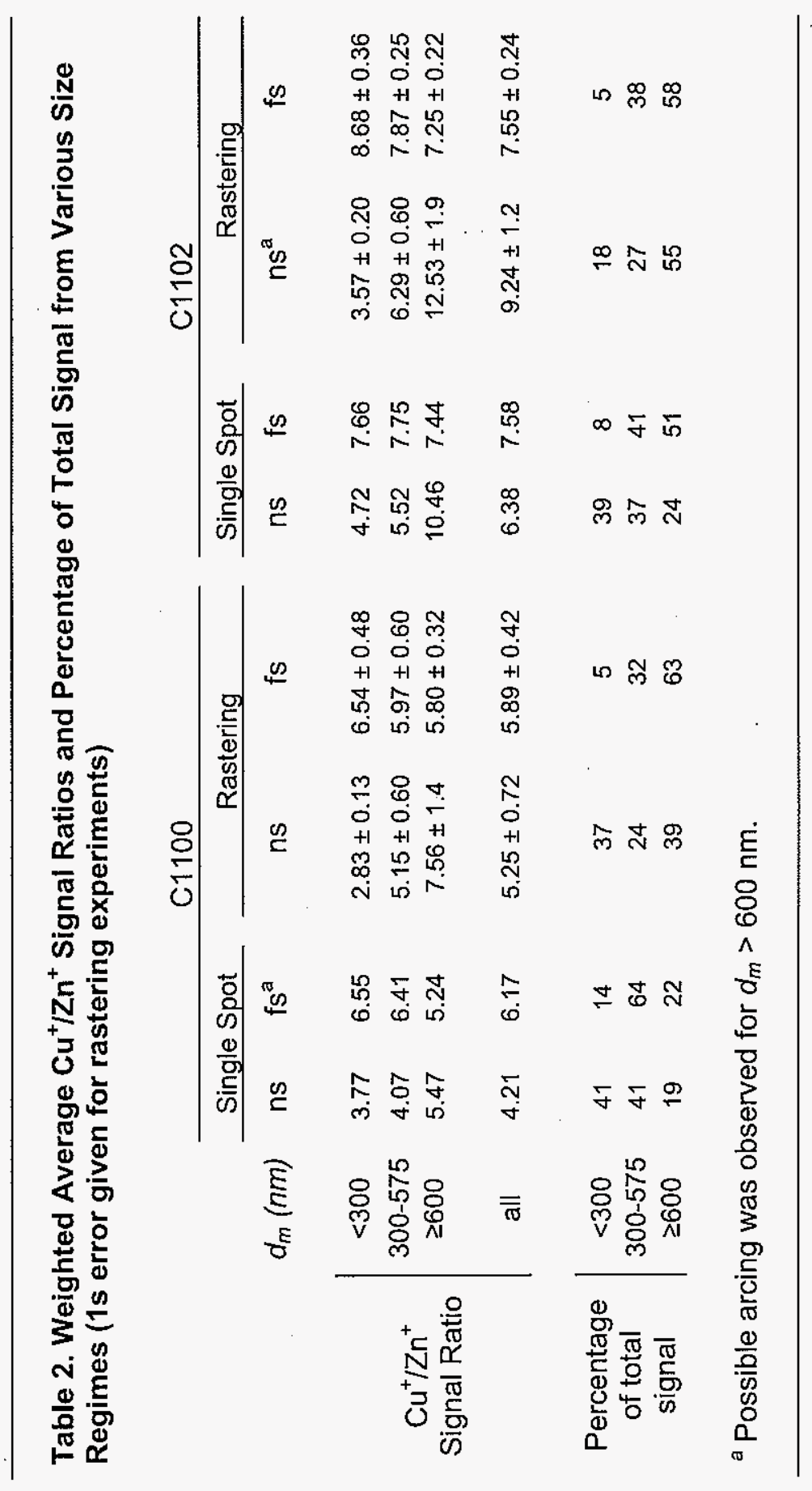


Table 3. Ratio of the $\mathrm{Cu}^{+} / \mathrm{Zn}^{+}$Signal Ratios for $\mathrm{C} 1102 / \mathrm{C} 1100$ in Various $d_{m}$ Regimes (Calculated from Certified Values: 1.284)

\begin{tabular}{|c|c|c|c|c|}
\hline \multirow[b]{2}{*}{$d_{m}(n m)$} & \multicolumn{2}{|c|}{ Nanosecond LA } & \multicolumn{2}{|c|}{ Femtosecond LA } \\
\hline & Single Spot & Rastering $^{a}$ & Single Spot ${ }^{a}$ & Rastering \\
\hline$<300$ & 1.25 & 1.26 & 1.17 & 1.33 \\
\hline $300-575$ & 1.36 & 1.22 & 1.21 & 1.32 \\
\hline$\geq 600$ & 1.91 & 1.66 & 1.42 & 1.25 \\
\hline all & 1.43 & 1.44 & 1.28 & 1.28 \\
\hline Possible & was observ & $\operatorname{or} d_{m}>600$ & & \\
\hline
\end{tabular}



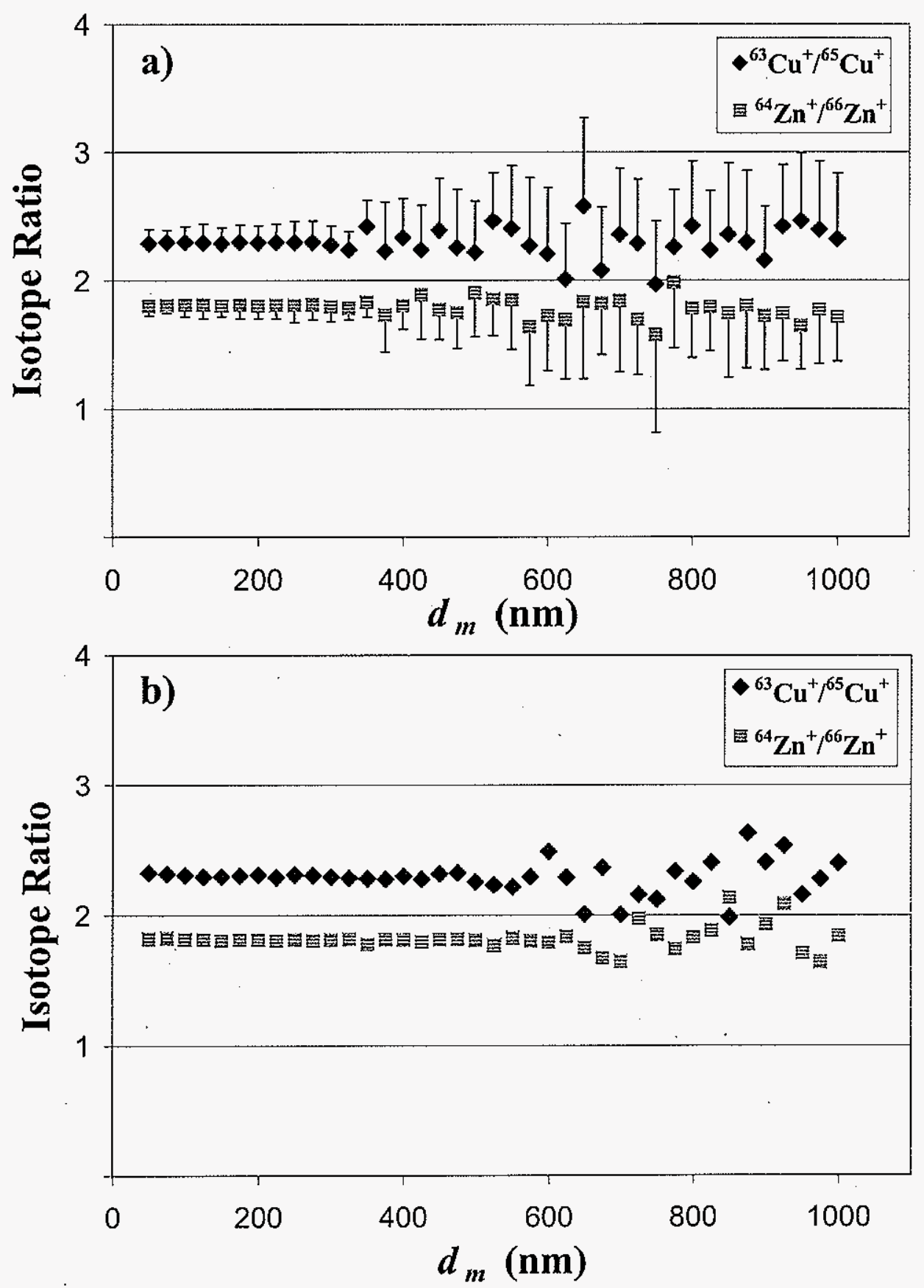

Figure 1. Isotope ratio plots for nanosecond LA of NIST C1100 brass: (a) rastering (1s error bars) and (b) single spot. For clarity, only the upper or lower halves of error bars are shown in (a). 

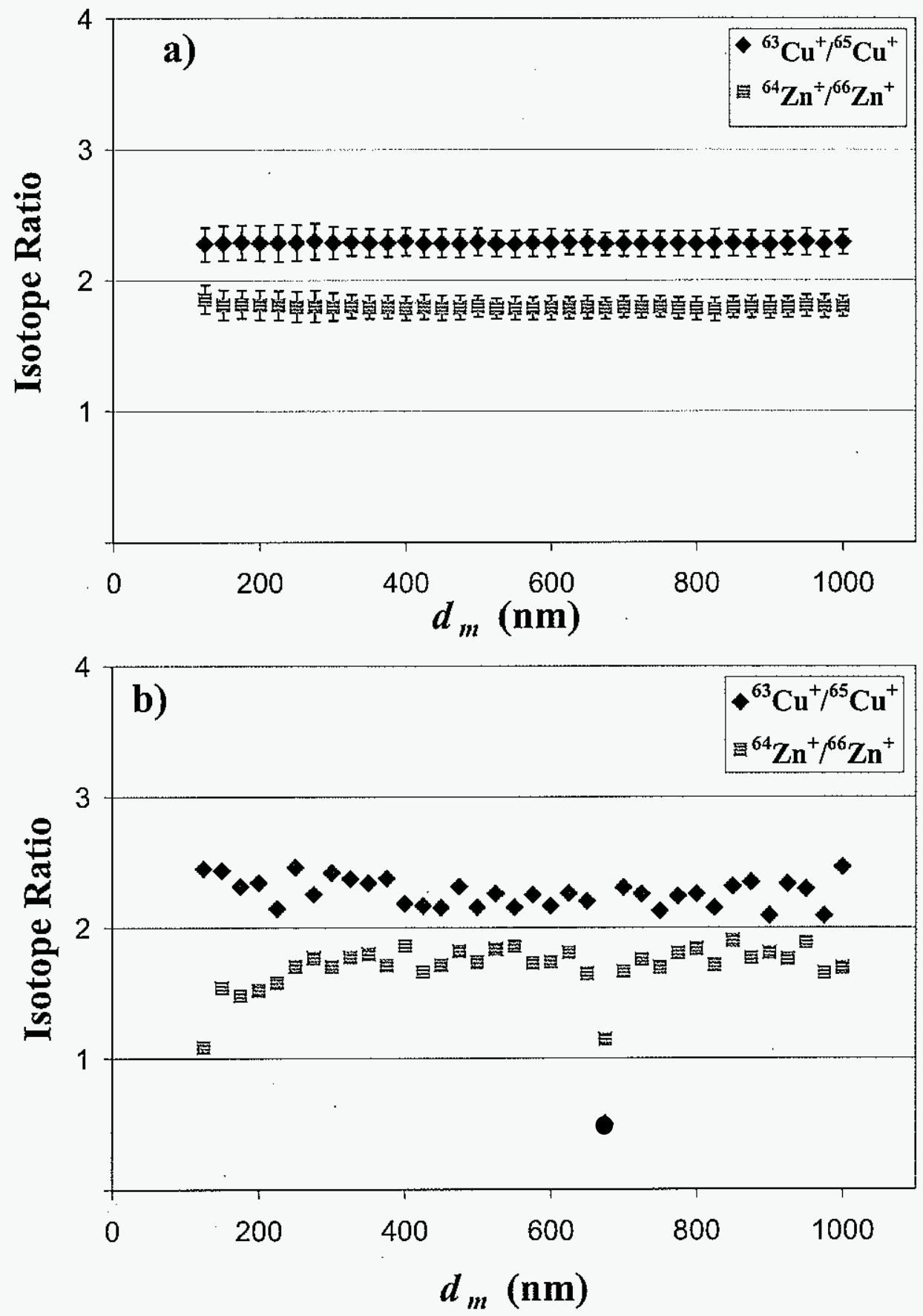

Figure 2. Isotope ratio plots for femtosecond LA of NIST C1102 brass: (a) rastering (1s error bars) and (b) single spot. 

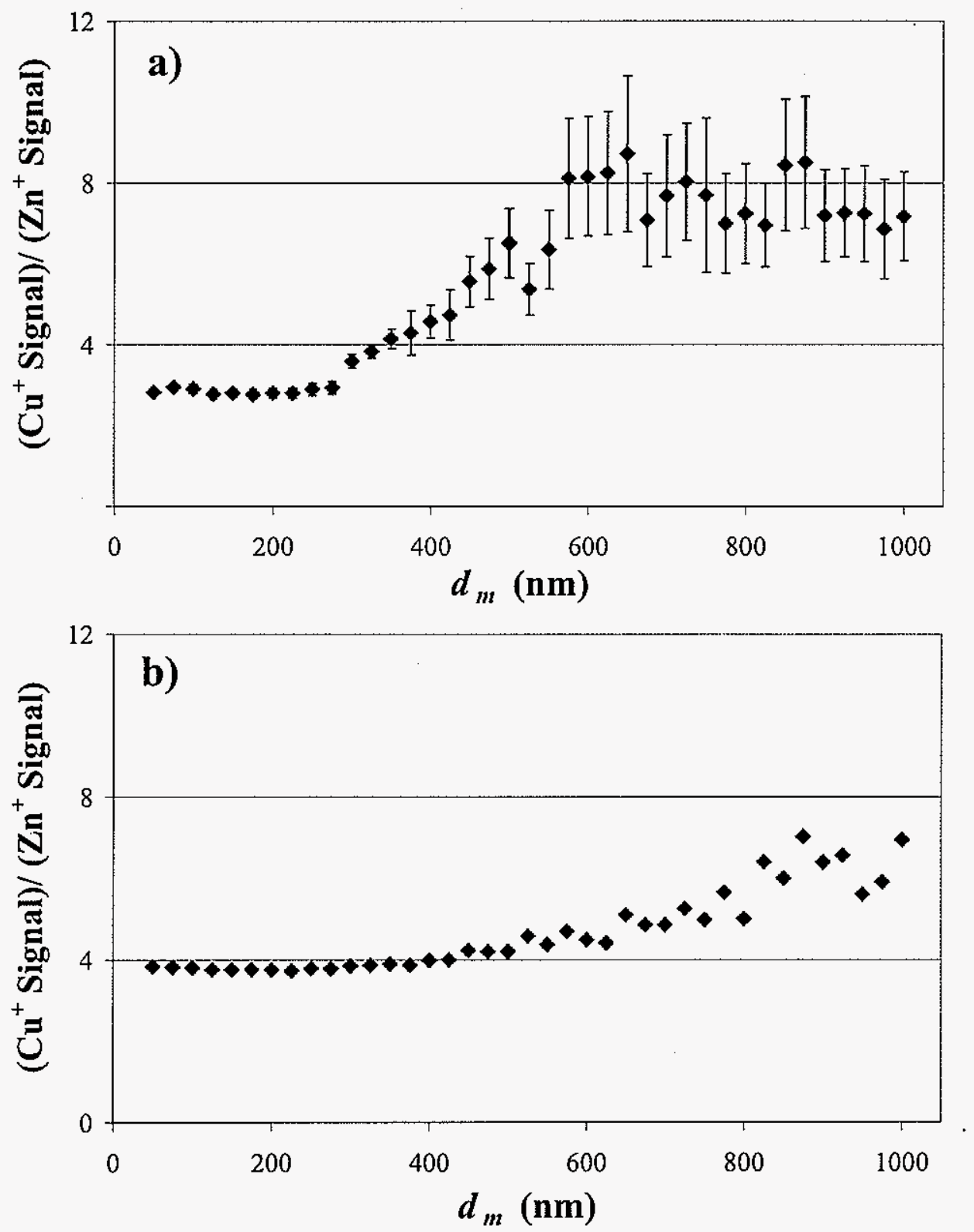

Figure 3. Normalized elemental ratio plots for nanosecond LA of NIST C1100 brass, (a) rastering (1s error bars) and (b) single spot. 

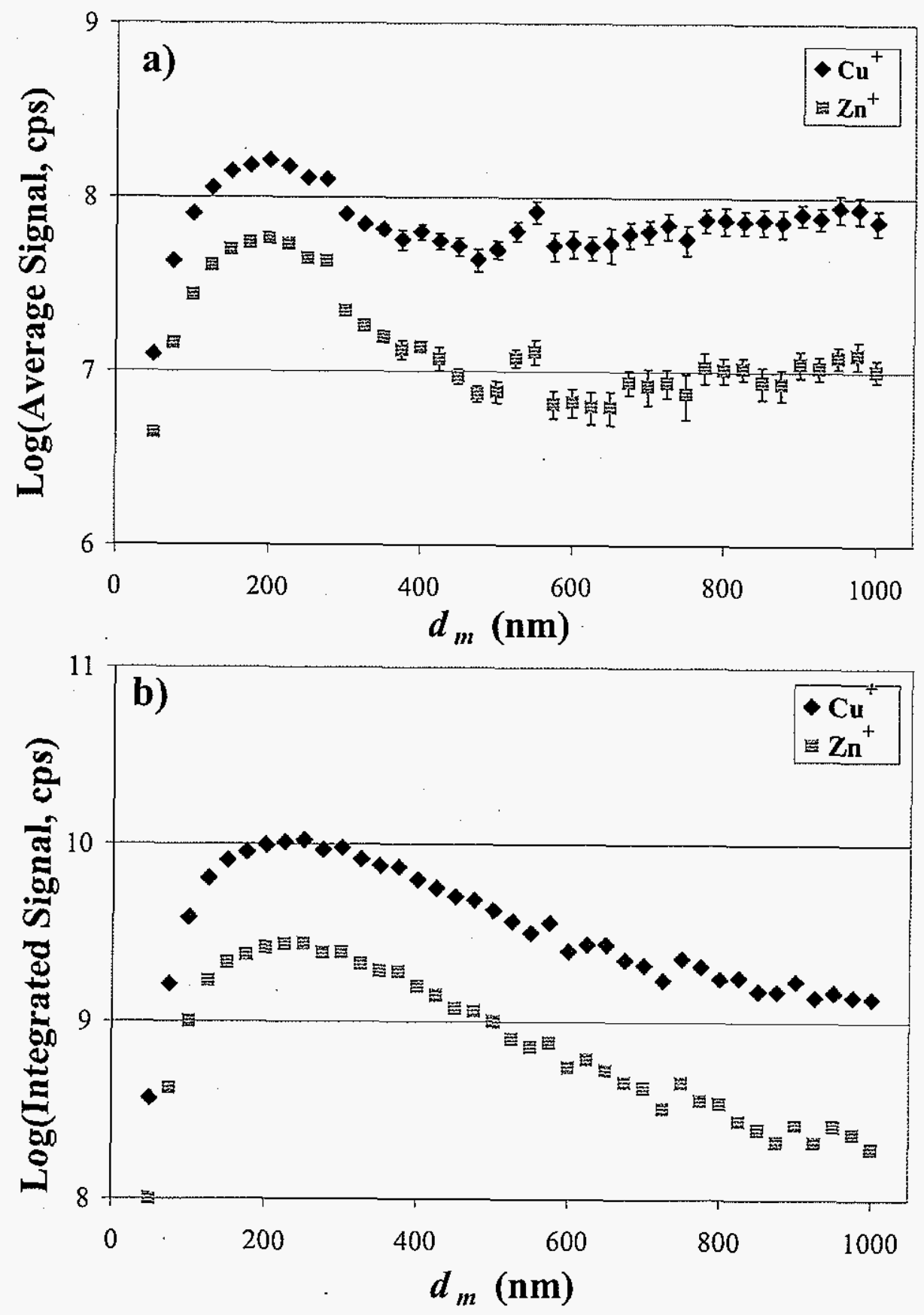

Figure 4. Signal plots for nanosecond LA of NIST C1100 brass: (a) rastering (1s error bars) and (b) single spot. 

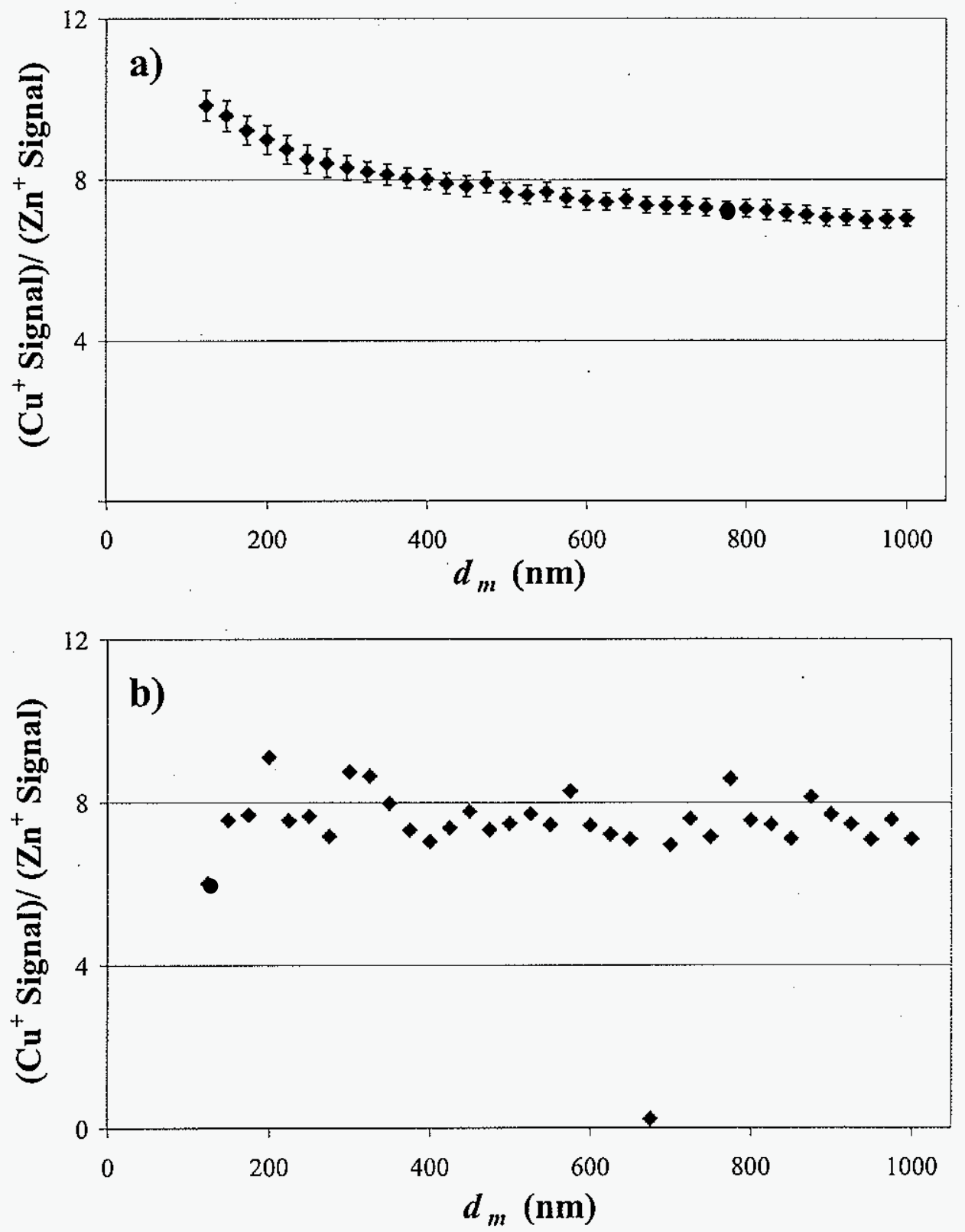

Figure 5. Normalized elemental ratio plots for femtosecond LA of NIST C1102 brass: (a) rastering (1s error bars) and (b) single spot. 

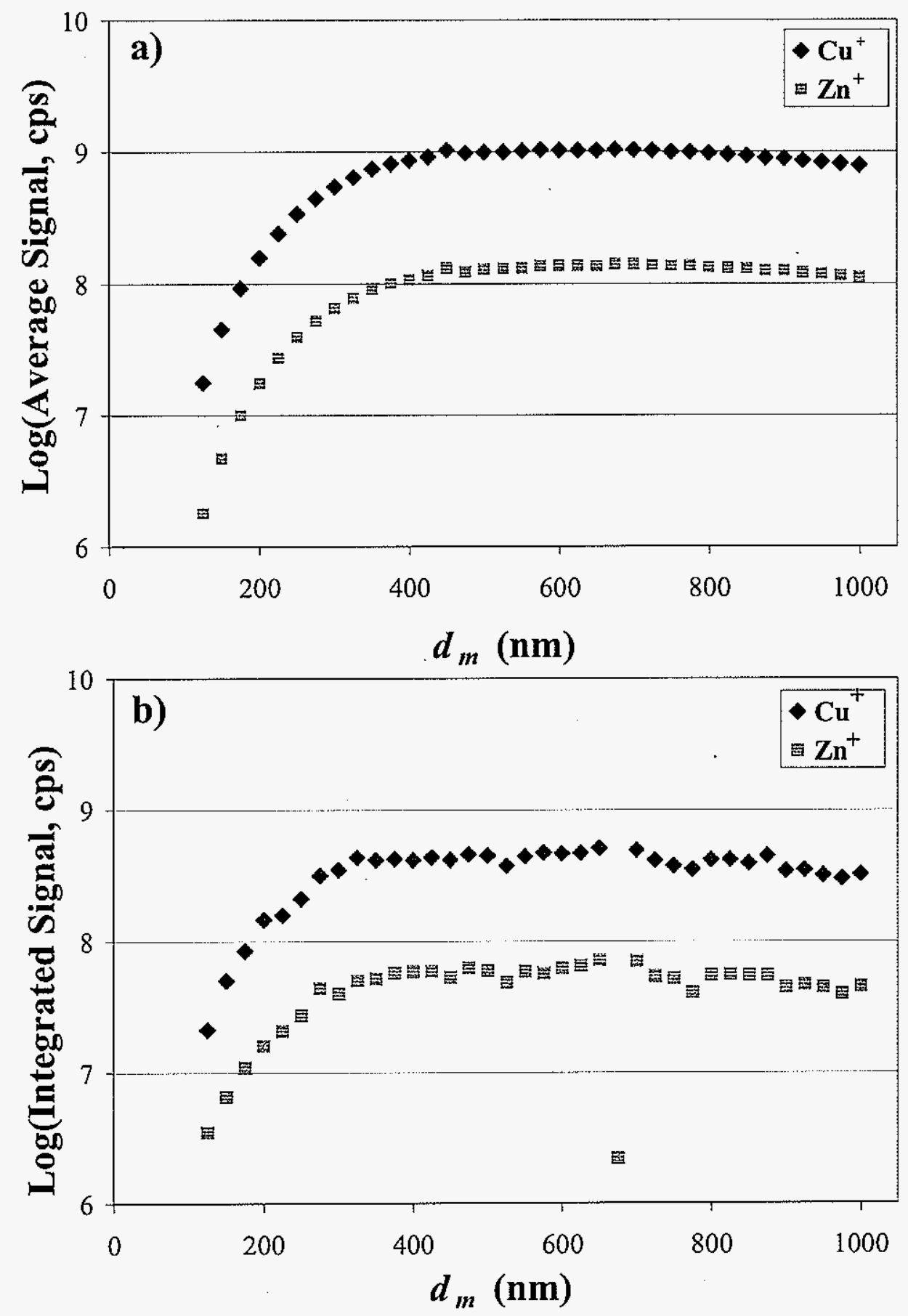

Figure 6. Signal plots for femtosecond LA of NIST C1102 brass: (a) rastering ( $1 \mathrm{~s}$ error bars) and (b) single spot. Note that error bars in (a) are smaller than the symbols. 

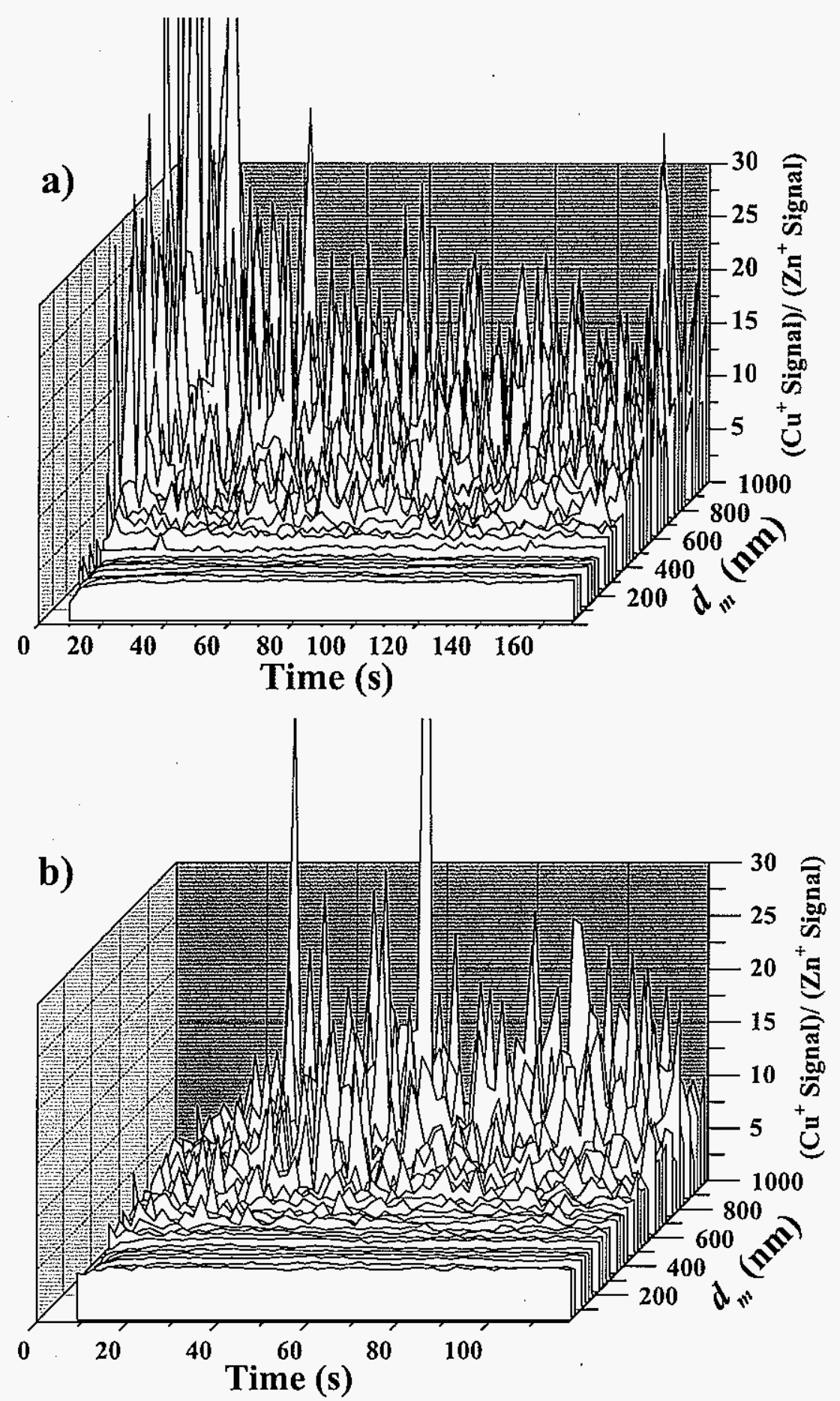

Figure 7. Time stability of nanosecond LA: (a) rastering and (b) single spot. 


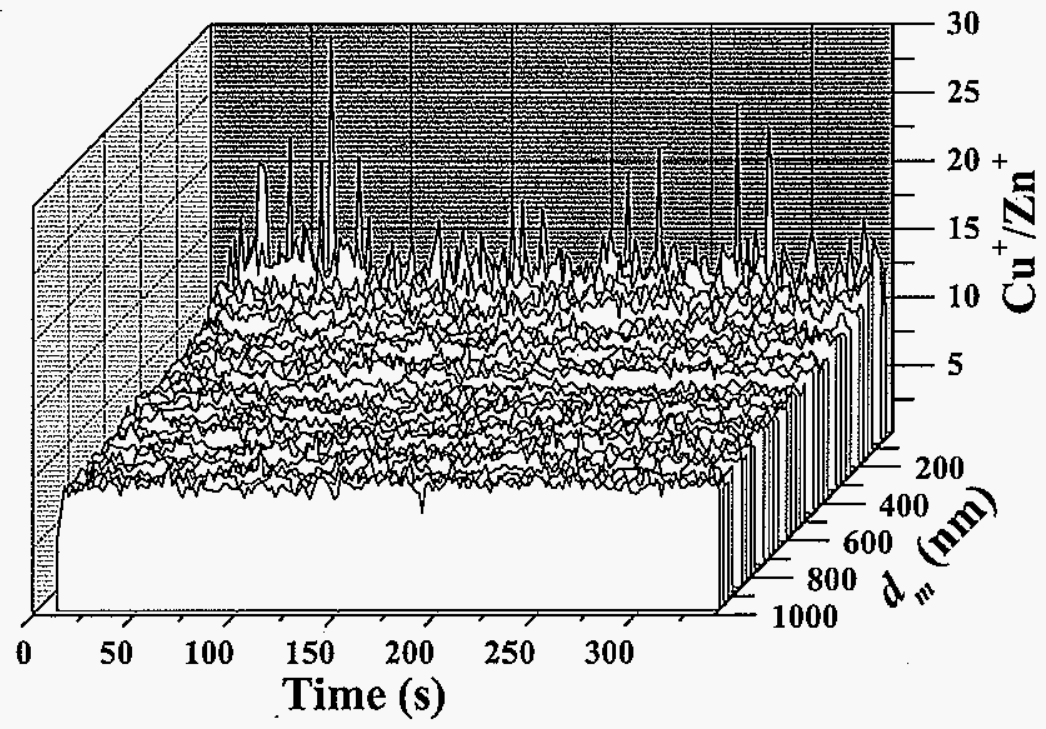

Figure 8. Time stability of femtosecond rastering LA. Note that the $d_{m}$ axis is reversed as compared with Fig. 7. 


\title{
Chapter 3. High-speed digital photographic study of an inductively coupled plasma: single particle behavior from solution nebulization and laser ablation
}

\author{
A paper to be submitted to the Journal or Analytical Atomic Spectrometry \\ Nathan J. Saetveit, Daniel S. Zamzow, Christopher H. Ebert, David P. Baldwin, and R. S. \\ Houk
}

\begin{abstract}
A digital video camera with a $<20 \mu$ s shutter speed and a frame rate $>10,000$ frames per second (fps) was used to examine individual droplets and particles traveling through an inductively coupled plasma (ICP). Large droplets containing Y were introduced into an ICP via solution nebulization, and NIST 610 glass and a $\mathrm{Y}_{2} \mathrm{O}_{3}$ pellet were ablated with a nanosecond laser in $\mathrm{Ar}$ and $\mathrm{He}$. Single droplets or particles were followed in successive frames in high-speed digital videos. Spatially resolved emission was observed for $\mathrm{Na}$ and $\mathrm{Ca}$ in NIST 610 glass. Emission profiles from $\mathrm{Na}, \mathrm{Ca}$, and Si were obtained from solution nebulization in Ar and $\mathrm{He}$ to provide insight into particle emission from those elements during laser ablation of glass. Ablation in He led to emission lower in the plasma, more diffuse emission clouds, and a wider normal analytical zone (NAZ).
\end{abstract}




\section{Introduction}

Inductively coupled plasma mass spectrometry (ICP-MS) and atomic emission spectroscopy (ICP-AES) are established analytical techniques for the determination of trace elements in a variety of samples. ${ }^{1-3}$ The behavior of sample droplets and particles in an ICP is of interest for the optimization of analytical performance and fundamental understanding of processes in an ICP.

The presence of particles in the ICP from laser ablation (LA), a popular sampling method for ICP-MS, ${ }^{4-6}$ has been implicated as a source of elemental fractionation, defined here as a discrepancy between determined elemental ratios and the actual stoichiometry of a sample. $^{7-14}$ Studies of non-matrix matched calibration methods for LA-ICP-MS involving simultaneous introduction aerosol from solution nebulization and aerosols from LA indicate that the behavior of wet and dry particles in the plasma may affect calibration. ${ }^{15-20}$

Photography, other imaging techniques, and fast data acquisition have been used to study droplet and particle behavior in an ICP. Cicerone and Famsworth studied gas flow velocities by monitoring analyte emission in an ICP. ${ }^{2 !}$ Olesik et al. used optical emission and laser-induced fluorescence to examine the behavior of droplets and particles in an ICP. ${ }^{22,}$ ${ }^{23}$ Houk et al. used high speed analog photography to image droplets and particles of $Y$ from various sources. ${ }^{24,25}$ More recently, Aeschliman et al. used a digital camera with a shutter speed of $63 \mu$ s to take high resolution still photographs of particles in an ICP and a digital camcorder to record videos at a maximum rate of $30 \mathrm{fps}^{26} \mathrm{Li}$ et al. and Perdian et al. studied particle behavior in ICP-MS by fast data acquisition and attributed large signal spikes on a $\sim 5 \mathrm{~ms}$ time frame to the presence of intact particles in the ion extraction region of the $\mathrm{ICP} .^{8,9}$, 
The present work uses a digital video camera with both a fast shutter speed $<20 \mu \mathrm{s}$ and high frame rate $>10,000 \mathrm{fps}$ to digitally photograph individual droplets and particles as they travel through an ICP. Large droplets from a solution containing $Y$ as well as individual particles produced by nanosecond LA of $\mathrm{Y}_{2} \mathrm{O}_{3}$ and NIST 610 glass are examined.

\section{Experimental}

\section{ICP Conditions}

The ICP generator, matching network, and torch box is an RF Plasma Products model ICP-16L operating at $40 \mathrm{MHz}$ RF frequency and a forward RF power of $1100 \mathrm{~W}$. Gas flow rates were set with rotameters with nominal Ar gas flow rates of $15 \mathrm{~L} \mathrm{~min}^{-1}, 0.5 \mathrm{~L} \mathrm{~min}^{-1}$, and

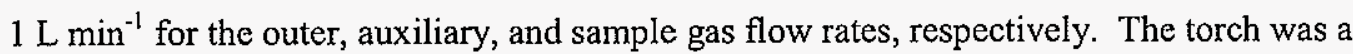
Fassel type with a $1.5 \mathrm{~mm}$ ID injector and was oriented vertically. A quartz window was placed over the opening of the torch box to lessen plasma instability from external air currents. The plasma used in this study is very rugged and was able to run with $100 \% \mathrm{He}$ sample gas during the He LA experiments. To compare the initial radiation zone (IRZ) and normal analytical zone (NAZ) with Ar versus He sample gas flows, the He sample gas flow rate was set to be nominally equivalent to the Ar sample gas flow rate using an Air Products E29-4-150 $\mathrm{mm}^{3}$ rotameter (Allentown, PA, USA) that was calibrated for He. During the solution nebulization experiments with He as a sample gas, plasma instability was attenuated by decreasing the He gas flow rate by $20 \%$ and mixing Ar into the sample gas flow to bring the total volume flow rate to nominally $1 \mathrm{~L} \mathrm{~min}^{-1}$. 


\section{Photographic equipment and parameters}

The camera was an Olympus i-Speed2 color camera (Olympus Corporation, Tokyo, Japan). The images of nebulized Y solution were taken with a $12.5 \mathrm{~mm} f / 1.4$ Pentax lens at $5000 \mathrm{fps}$ and a shutter time of $10 \mu \mathrm{s}$. All other images were taken with a $25 \mathrm{~mm} / 1.4$ Navitron camera lens at $10,000 \mathrm{fps}$ and a shutter time of $20 \mu \mathrm{s}$. The camera is capable of recording up to $33,000 \mathrm{fps}$ with a shutter speed of $6.06 \mu \mathrm{s}$. The fastest shutter speed is $5 \mu \mathrm{s}$, available at frame rates $\leq 20,000 \mathrm{fps}$. Resolution and intensity decrease significantly at higher frame rates and shutter speeds, so the frame rates and shutter times were chosen to balance resolution, intensity, and contrast between particle clouds and the background of the ICP.

\section{Laser ablation}

A CETAC Technologies LSX-500 LA system was used for nanosecond LA. The laser is a Q-switched, beam-homogenized, frequency-quadrupled (266 nm) Nd:YAG laser. The sample is placed on a movable $x y z$-translation stage, and ablation can be visually monitored in real time with a charge-coupled device (CCD) and a zoom lens. A pulse width of $<6 \mathrm{~ns}$, raster speed of $100 \mu \mathrm{s} \mathrm{s}^{-1}$, and energy specified to be $\sim 9 \mathrm{~mJ}$ per pulse were used for all experiments. For LA of $\mathrm{Y}_{2} \mathrm{O}_{3}$, a repetition rate and spot size of $5 \mathrm{~Hz}$ and $50 \mu \mathrm{m}$ were chosen for most experiments to generate many isolated particles in the ICP. LA of silicates produces fewer and smaller particles than LA of a pressed powder pellet since it does not break apart as easily when ablated, so a faster repetition rate $(10 \mathrm{~Hz})$ and a larger spot size $(100 \mu \mathrm{m})$ were used for LA of NIST 610 to increase the number of particles observed. Some 
experiments with $\mathrm{Y}_{2} \mathrm{O}_{3}$ were done under the same conditions as the NIST 610 experiments in order to view more multiple particle events in the ICP.

\section{Samples and Conditions}

Two solid samples were used: NIST 610 glass and a pressed pellet of $\mathrm{Y}_{2} \mathrm{O}_{3}$ powder mixed $\sim 1: 1$ by weight with Spectroblend binding agent (Chemplex Industries, Inc., Palm City, FL, USA). Both were ablated using $\mathrm{He}$ and $\mathrm{Ar}$ as sample gases.

Large droplets containing $Y$ were introduced into an ICP by nebulizing a $10,000 \mathrm{ppm}$ Y solution with a Meinhard nebulizer with 35 psi nebulizer pressure (approximately $0.65 \mathrm{~L}$ $\min ^{-1}$ ) and $1.9 \mathrm{~mL} \mathrm{~min}^{-1}$ sample delivery. The nebulizer was pumped faster than the normal rate in order to generate more larger droplets than would be produced via natural uptake or during normal analytical use. Large, wet droplets were desired to generate ion clouds that would be visible in successive video frames even though they are not wanted for ICP-MS analysis.

An ultrasonic nebulizer (USN) (Cetac Technologies, Omaha, NE, USA) was used to introduce a solution of approximately $6,400 \mathrm{ppm} \mathrm{Si}, 2000 \mathrm{ppm} \mathrm{Na}$, and $1600 \mathrm{ppm} \mathrm{Ca}$ into the plasma. The concentrations of $\mathrm{Si}, \mathrm{Na}$, and $\mathrm{Ca}$ were chosen to approximate the makeup of the major constituents in NIST 610 glass. In addition, individual solutions of each of these elements were analyzed to obtain individual emission profiles for each element. Videos were acquired during sample introduction as well as after solution flowing to the nebulizer had stopped in order to view emission profiles at different intensities and as the solvent load decreased. The most instructive view was approximately 10 seconds after sample flow to the USN had stopped but while emission zones in the plasma were still clearly visible. The 
general location of the emission zones did not shift noticeably during this time, indicating that the solvent load did not dramatically alter the location of the emission zones in the ICP. Results shown in this work are derived from videos taken at approximately the same time after stopping the solution flow to the USN for all samples.

\section{Results and Discussion}

\section{Introduction of large, wet droplets}

Video sequences show many individual particle clouds exiting the IRZ and traveling through the plasma. Figure 1 and Video 1show the emission cloud surrounding a typical large wet droplet containing $Y$ throughout its lifetime in the plasma. As expected based on previous studies, faint red emission from neutral YO is observed from the droplet in the IRZ. Previous studies have consistently observed this emission from wet droplets containing Y. As the droplet enters the NAZ, a white emission cloud with a red tinge in the center is visible, likely resulting from a mix of neutral $\mathrm{Y}$ and $\mathrm{YO}$. The $\mathrm{IRZ}$ also contains intense blue emission background from $\mathrm{Y}^{+}$in many small droplets. While the large droplet is assumed to be on the order of $<10 \mu \mathrm{m}$, the emission cloud is initially $\sim 1.5 \mathrm{~mm}$ in diameter. As the droplet travels downstream in the plasma, the surrounding vapor cloud becomes larger and more diffuse, showing increasingly more $\mathrm{Y}^{+}$emission. Droplets introduced by nebulization are remarkably centered in the plasma, and many large droplets survive all the way through the ICP. 


\section{Laser ablation of $\mathrm{Y}_{2} \mathrm{O}_{3}$}

Compared to solution nebulization, $\mathrm{LA}$ of $\mathrm{Y}_{2} \mathrm{O}_{3}$ in Ar produced much less background $\mathrm{Y}^{+}$emission, more multiple particle events, and no clearly defined IRZ. Figure 2 and Video 2 show a typical cluster of emission clouds under these conditions. Aeschliman et $a l .^{26}$ observed a faint red IRZ during $\mathrm{LA}$ of $\mathrm{Y}_{2} \mathrm{O}_{3}$ under similar conditions with a camera with higher spatial resolution, but this faint red IRZ is likely indistinguishable from the background with the faster shutter speed in the current work. A single particle traveling through the ICP is shown in Figure 3 and Video 3. Emission from this dry particle is not observed until it is in the middle of the NAZ, a few mm downstream from the IRZ. As the particle travels downstream, emission intensity increases from the center of the particle even as the emission cloud becomes larger and more diffuse. Red YO emission isn't observed until the particle reaches the tail of the plasma and is exposed to entrained atmospheric $\mathrm{O}_{2}$. As in solution nebulization, many large ion clouds are observed traveling through the entire length of the ICP.

Using He instead of Ar as a sample gas causes the ablated aerosol to heat more quickly because He has a higher thermal conductivity than $\mathrm{Ar}^{28}$ This causes vaporization, atomization, and ionization to occur farther upstream in the plasma and the ion clouds to grow larger and more diffuse relative to those observed when the sample gas is Ar only. Figure 4 shows a dramatic difference between the ion clouds for particles at approximately the same axial position in the plasma ablated in He versus Ar. The frames shown in Figure 4 are typical of the behavior observed for many particles under both conditions. It is assumed that these particles are of similar size even though LA in He generally produces smaller particles than LA in $\mathrm{Ar}^{29}$ Since the $\mathrm{Y}_{2} \mathrm{O}_{3}$ pellet breaks apart easily, it is likely that many of 
the particles entering the plasma during both Ar and He LA are simply dislodged particles from the surface of the pellet and that there is not a dramatically different size distribution. If LA of the $\mathrm{Y}_{2} \mathrm{O}_{3}$ pellet in $\mathrm{He}$ does produce a distribution of smaller particles than that for $\mathrm{Ar}$ LA, then the effects of He in the ICP are even more pronounced than is evident in Figure 4.

\section{Emission profiles from $\mathrm{Na}, \mathrm{Ca}$, and $\mathrm{Si}$}

Although the plasma conditions differ somewhat during solution nebulization compared to laser ablation due to differences in matrix load, the general zones where emission occurs during solution nebulization provide insight into emission observed from ablated glass particles containing these elements. Single element solutions containing only $\mathrm{Na}, \mathrm{Ca}$, or $\mathrm{Si}$, respectively, provide unique emission profiles. Figure 5 shows distinct emission characteristics from sample introduction in an Ar sample stream for each element nebulized separately, as well as from a water blank and from a solution of all 3 elements. $\mathrm{Na}$ I emission (orange, $\sim 589 \mathrm{~nm}$ ) is observed most strongly in the IRZ, whereas Ca II emission (purple, $\sim 393$ and $\sim 396 \mathrm{~nm}$ ) is mostly observed in the NAZ farther downstream. While not intense in the visual spectrum, blue Si I emission is seen around the edges of the IRZ when Si is introduced by itself. The superimposed emission profiles of $\mathrm{Na}$ and $\mathrm{Ca}$ are most visible in the photographs of the mixture, whereas Si emission is masked by the more intense emission from the other elements.

Of particular interest is whether some observed emission was predominantly from a single element or the combination of emission from more than one element. While there is some memory in this experiment given the high elemental concentrations introduced, the light purple emission observed from Ca solution introduction appears to be predominantly 
from $\mathrm{Ca}$ and not a mixture of $\mathrm{Ca}$ and $\mathrm{Na}$ emission, which is instructive while investigating LA particles from NIST 610.

Figure 6 shows photos of the ICP when solutions are introduced with predominantly $\mathrm{He}$ as a sample gas. The structure of the ICP and emission profiles for $\mathrm{Na}$ and $\mathrm{Ca}$ are markedly distinct from sample introduction with Ar. The IRZ appears to be shifted out of view of the camera, causing much of the Na emission to be upstream and out of view of the camera. The Ca emission profile is also clearly shifted upstream relative to the emission profile with Ar sample gas. Additionally, the NAZ is significantly broadened by the presence of He due to greater heating and diffusion.

\section{Laser ablation of NIST 610 glass}

Particle clouds from LA of NIST 610 glass tend to be smaller; less intense, and less frequent than $\mathrm{Y}_{2} \mathrm{O}_{3}$ particles, but enough emission is observed to identify at least $\mathrm{Na}$ and $\mathrm{Ca}$ emission from distinct particles when using $\mathrm{Ar}$ as a sample gas. Figure 7 and Video 4 show an example of a single particle traveling through the plasma. Near the tip of the IRZ (not visible in the photographs), distinct $\mathrm{Na}$ I emission is observed confined to a small orange cloud around the particle. Consistent with the emission profiles obtained from solution introduction, the orange $\mathrm{Na}$ emission in Frames 2 and 3 begins to show a mix of what appears to be purple Ca II emission in the NAZ as the cloud expands and travels downstream. This indicates the possibility of vaporization, atomization, and ionization occurring at different locations in the plasma for $\mathrm{Na}$ and $\mathrm{Ca}$, which could be a cause of elemental fractionation. Finally, as the particle exits the plasma (Frame 11), the emission is 
essentially entirely from $\mathrm{Ca}$. This progression was observed consistently for single ablated glass particles as they travel through the ICP.

Occasionally, $\mathrm{Ca}$ emission was observed at a similar height in the plasma as $\mathrm{Na}$ emission for different particles that entered the plasma slightly off-center. Figure 8 and Video 5 show an example of a pair of distinct particles introduced in He showing separate $\mathrm{Na}$ and $\mathrm{Ca}$ emission in close proximity.

LA of NIST 610 in He resulted in mostly very small particles with faint emission. Similar to other results in this work, Na emission is not observed in He and is likely occurring farther upstream in the plasma than is visible with the camera. Figure 9 and Video 6 show a typical small particle introduced with He sample gas. Fewer large particles from LA with $\mathrm{He}$ is consistent with less fractionation and a more stoichiometric aerosol as has been reported elsewhere. ${ }^{11,29,30}$ Occasionally, single large particles were observed during LA with He. Figure 10 and Video 7 show an example of such a larger particle, with predominantly $\mathrm{Ca}$ emission. There may be slight emission from $\mathrm{Na}$ from these particles, but comparing the emission to the Ca-only solution indicates that most of the observed emission arises from $\mathrm{Ca}$.

\section{Particle velocity}

Particle velocity was estimated using the frame rate and the distance traveled between frames. The outer diameter of the torch is $20 \mathrm{~mm}$, which provides a scale for estimating distance. Particle velocity was found to be approximately $20 \mathrm{~m} \mathrm{~s}^{-1}$ for particles in both $\mathrm{Ar}$ and $\mathrm{He}$, which is somewhat lower than previously reported values between $27-35 \mathrm{~m} \mathrm{~s}^{-1}$ but 
reasonably consistent considering the lower gas flow in the present work and/or lower temporal resolution in previous works. ${ }^{21,25,26}$

\section{Conclusions}

The fast shutter speed and high frame rate used in this study provide an advantage over previous photographic studies for the investigation of droplets and particles in an ICP. Following individual particles through the plasma gives greater insight into emission behavior of particles at different locations in the plasma. Vaporization, atomization, and ionization of different elements in individual particles at different locations in the ICP may cause or contribute to ICP-induced elemental fractionation. Nanosecond LA generates particles large enough to traverse the length of the ICP under most conditions, which may also contribute to elemental fractionation.

Especially in Ar, many LA particles survive much farther downstream in the plasma than where extraction would occur in a mass spectrometer, which can contribute to elemental fractionation. Although the problem is attenuated somewhat by using He as a sample gas, some larger particles still survive past the extraction region in mass spectrometry, making it difficult to find a single good spot to sample ions during LA sample introduction.

\section{Acknowledgements}

SPEX-CertiPrep donated the standard solutions. Ames Laboratory is operated for the U. S. Department of Energy (USDOE) by Iowa State University of Science and Technology under Contract No. DE-AC02-07CH1 1358. This work was supported by the USDOE, Office 
of Defense Nuclear Nonproliferation, Office of Nonproliferation Research and Engineering, NA-22.

\section{References}

1. R. S. Houk, V. A. Fassel, G. D. Flesch, H. J. Svec, A. L. Gray and C. E. Taylor, Anal. Chem., 1980, 52, 2283-2289.

2. K. E. Jarvis, A. L. Gray and R. S. Houk, Handbook of Inductively Coupled Plasma Mass Spectrometry, Chapman and Hall, New York. 1992.

3. R. S. Houk and J. J. Thompson, Mass Spectrometry Reviews, 1988, 7, 425-461.

4. S. F. Durrant, J. Anal. At. Spectrom., 1999, 14, 1385-1403.

5. A. L. Gray, Analyst, 1985, 110, 551-556.

6. R. E. Russo, X. Mao and O. V. Borisov, Trends. Anal. Chem., 1998, 17, 461-469.

7. N. J. Saetveit, S. J. Bajic, D. P. Baldwin and R. S. Houk, J. Anal. At. Spectrom., 2008, 23, 54-61.

8. D. C. Perdian, S. J. Bajic, D. P. Baldwin and R. S. Houk, J. Anal. At. Spectrom., $2008,23,336-341$.

9. D. C. Perdian, S. J. Bajic, D. P. Baldwin and R. S. Houk, J. Anal. At. Spectrom., $2008,23,325-335$.

10. I. Kroslakova and D. Günther, J. Anal. At. Spectrom., 2007, 22, 51-62.

11. J. Koch, H. Lindner, A. von Bohlen, R. Hergenröder and K. Niemax, J. Anal. At: Spectrom., 2005, 20, 901-906.

12. H. R. Kuhn, M. Guillong and D. Günther, Anal. Bioanal. Chem., 2004, 378, $1069-$ 1074. 
13. H. R. Kuhn and D. Günther, Anal. Chem., 2003, 75, 747-753.

14. M. Guillong and D. Günther, J. Anal. At. Spectrom., 2002, 17, 831-837.

15. M. Wälle, J. Koch and D. Günther, J. Anal. At. Spectrom., 2008, DOI:

$10.1039 / \mathrm{b} 803563 \mathrm{f}$

16. Q. Bian, C. C. Garcia, J. Koch and K. Niemax, J. Anal. At. Spectrom., 2006, 21, 187191.

17. J. S. Becker, C. Pickhardt and H. J. Dietze, J. Anal. At. Spectrom., 2001, 16, 603-606.

18. C. O. Connor, B. L. Sharp and P. Evans, J. Anal. At. Spectrom., 2006, 21, 556-565.

19. D. B. Aeschliman, S. J. Bajic, D. P. Baldwin and R. S. Houk, J. Anal. At. Spectrom., $2003,18,872-877$.

20. J. J. Leach, L. A. Allen, D. B. Aeschliman and R. S. Houk, Anal. Chem., 1999, 71, $440-445$.

21. M. T. Cicerone and P. B. Farnsworth, in Spectrochim. Acta, Part B. 1989, vol. 44, p. 897.

22. J. W. Olesik, Appl Spectrosc, 1997, 51, 158A-175A.

23. J. W. Olesik, Appl Spectrosc, 1997, 51, 607-616.

24. R. K. Winge, J. S. Crain and R. S. Houk, J. Anal. At. Spectrom., 1991, 6, 601.

25. R. S. Houk, R. K. Winge and X. Chen, J. Anal. At. Spectrom., 1997, 12, 1139.

26. D. B. Aeschliman, S. J. Bajic, D. P. Baldwin and R. S. Houk, J. Anal. At. Spectrom., $2003,18,1008-1014$.

27. F. Li, D. W. Armstrong and R. S. Houk, Anal. Chem., 2005, 77, 1407-1413.

28. N. N. Sesi, A. Mackenzie, K. E. Shanks, Y. Pengyuan and G. M. Hieftje, Spectrochim. Acta, Part B, 1994, 49, 1259-1282. 
29. R. Hergenröder, J. Anal. At. Spectrom., 2006, 21, 1016-1026.

30. J. Koch, A. v. Bohlen, R. Hergenröder and K. Niemax, J. Anal. At. Spectrom., 2004, $19,267-272$. 

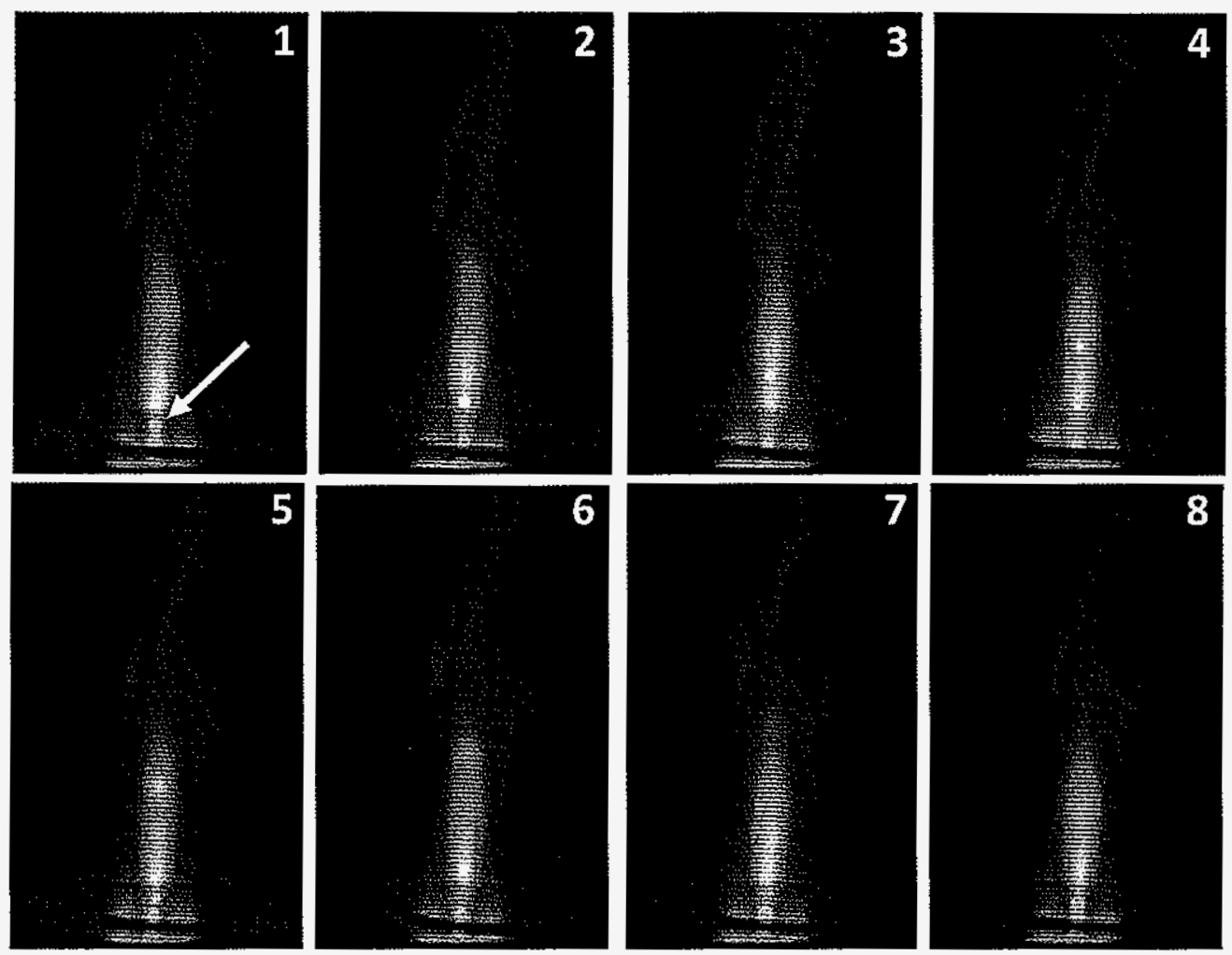

Figure 1. A large droplet containing $Y$ is observed traveling through the plasma in consecutive frames. Relative frame numbers are shown. 


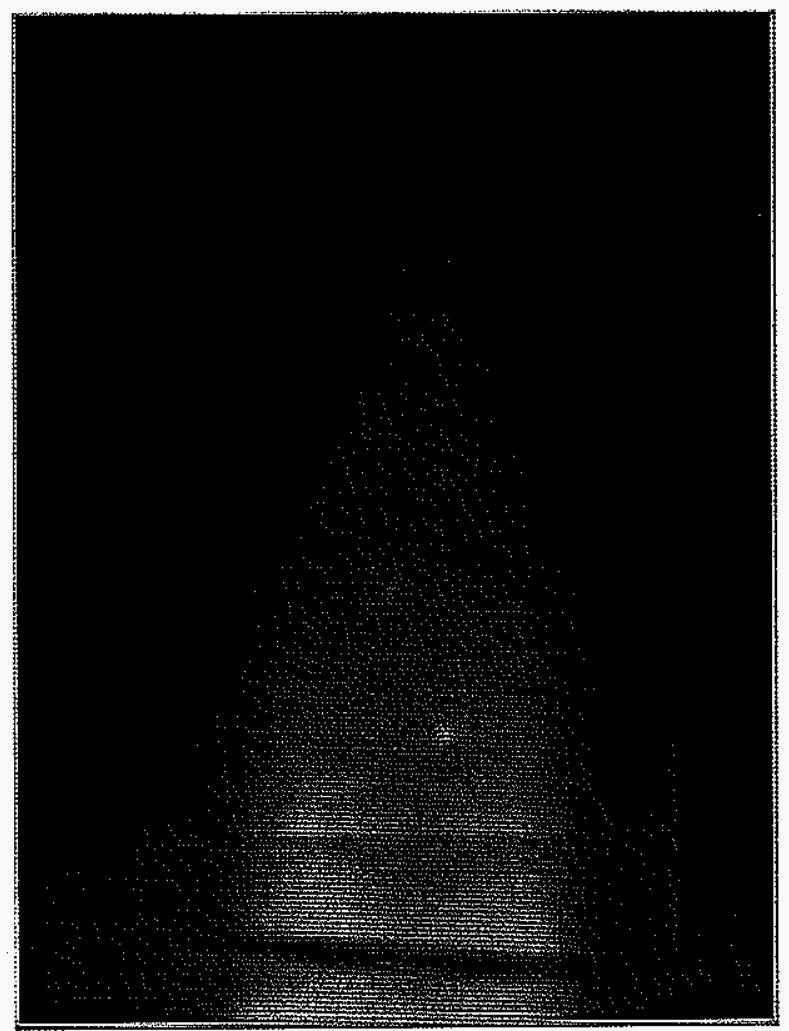

Figure 2. A typical cluster of emission clouds from $\mathrm{LA}$ of a $\mathrm{Y}_{2} \mathrm{O}_{3}$ pellet in $\mathrm{Ar}$ with a $10 \mathrm{~Hz}$ repetition rate and $100 \mu \mathrm{m}$ spot size. 

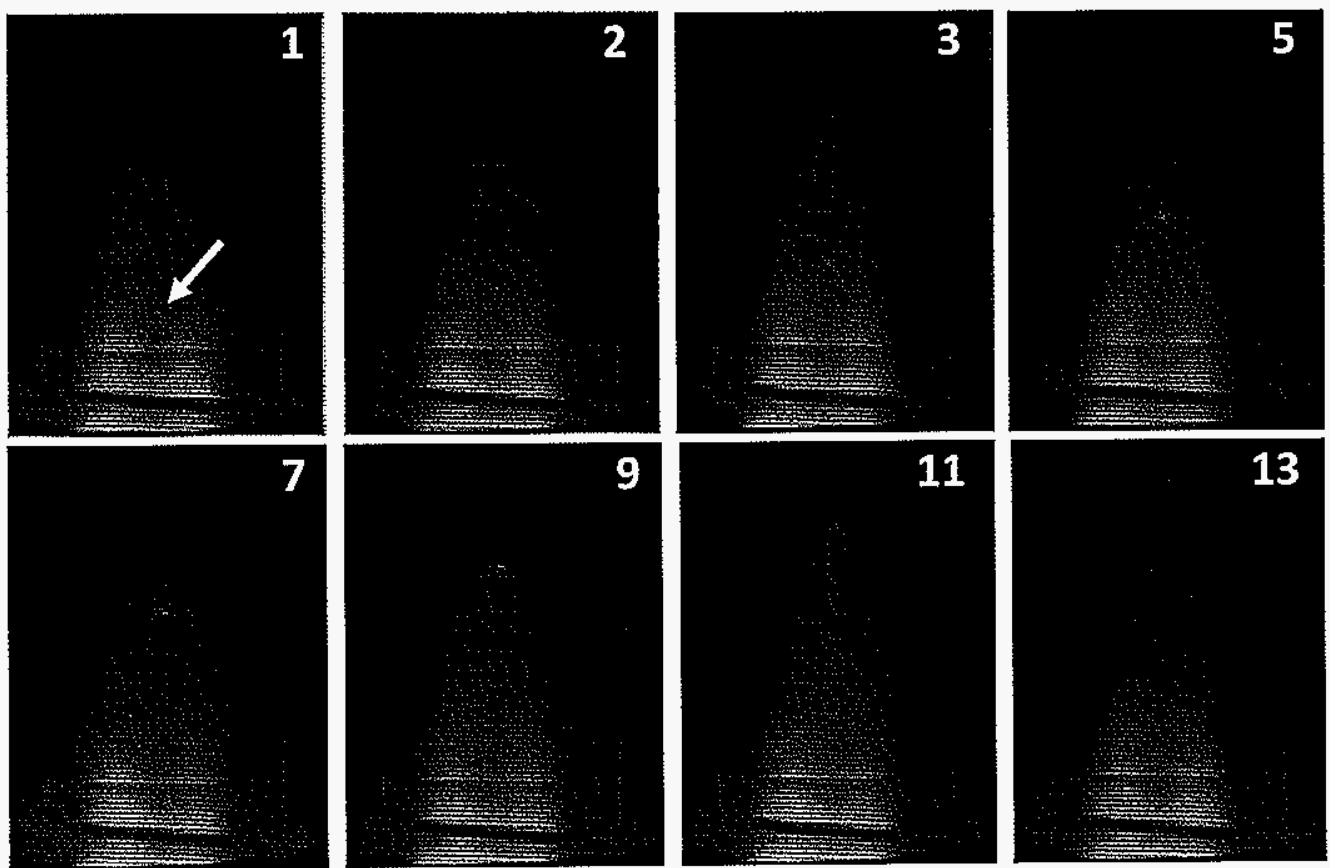

Figure 3. A single particle from laser ablation of a $\mathrm{Y}_{2} \mathrm{O}_{3}$ pellet in Ar. Relative frame numbers are shown. 

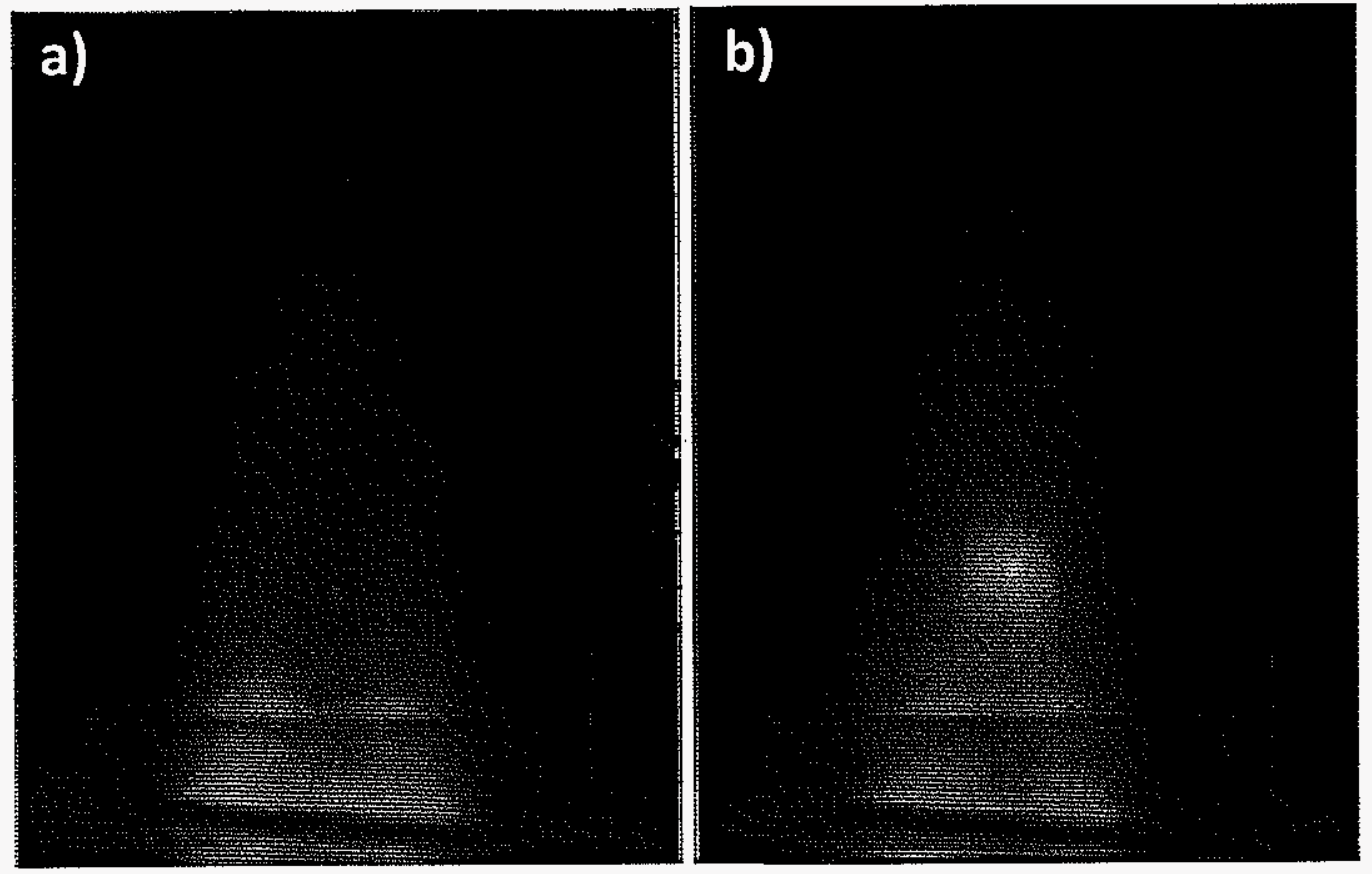

Figure 4. Representative emission cloud at approximately the same axial location in the ICP from a particle produced by $\mathrm{LA}$ of a $\mathrm{Y}_{2} \mathrm{O}_{3}$ pellet in a) $\mathrm{Ar}$ and b) $\mathrm{He}$. 

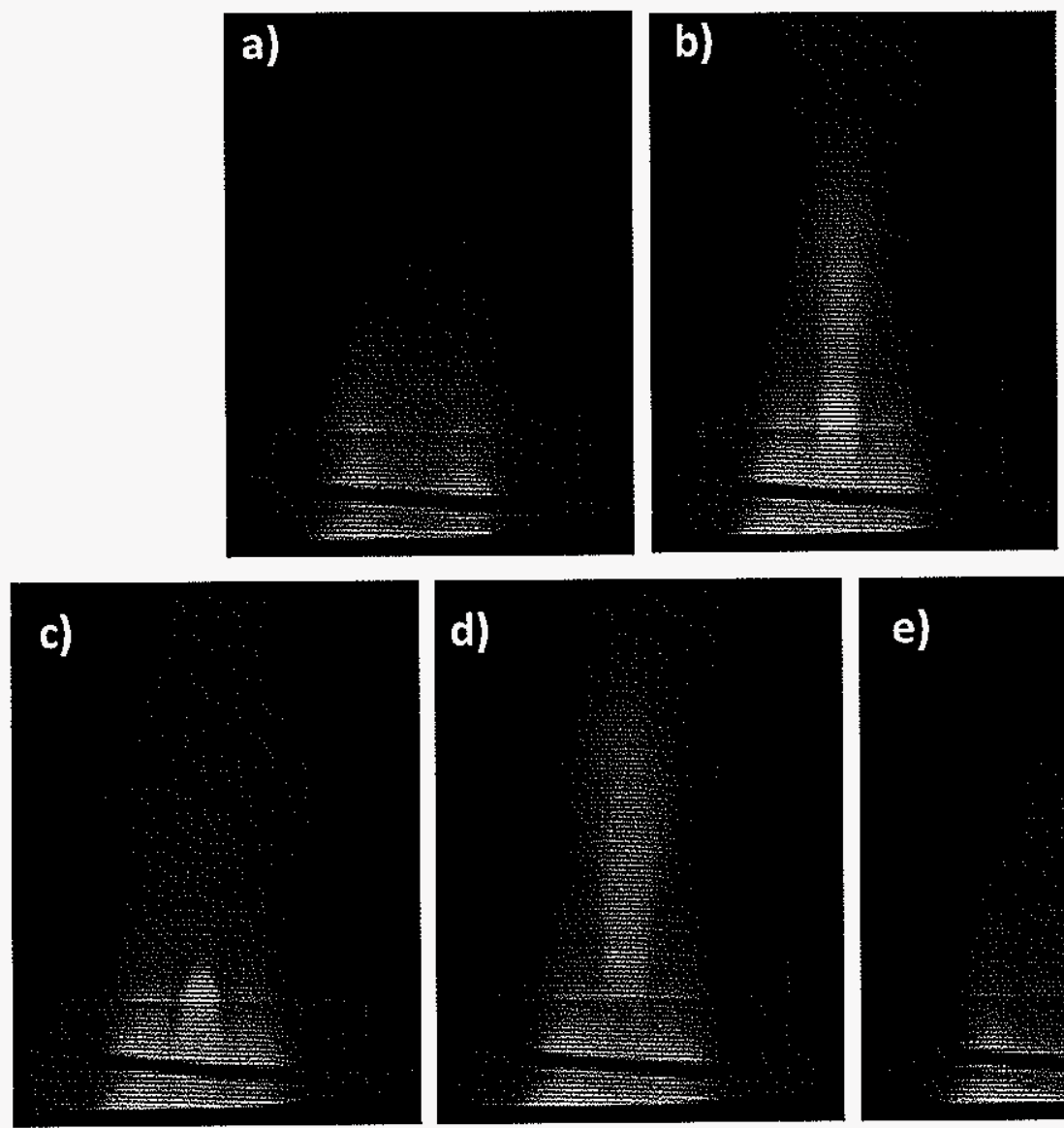

\section{e)}

Figure 5. Photographs of an ICP with Ar sample gas a) with no sample introduction, and approximately $10 \mathrm{~s}$ after stopping the introduction of b) $\mathrm{Na}, \mathrm{Ca}$, and $\mathrm{Si}$; c) $\mathrm{Na}$; d) $\mathrm{Ca}$; e) $\mathrm{Si}$. 

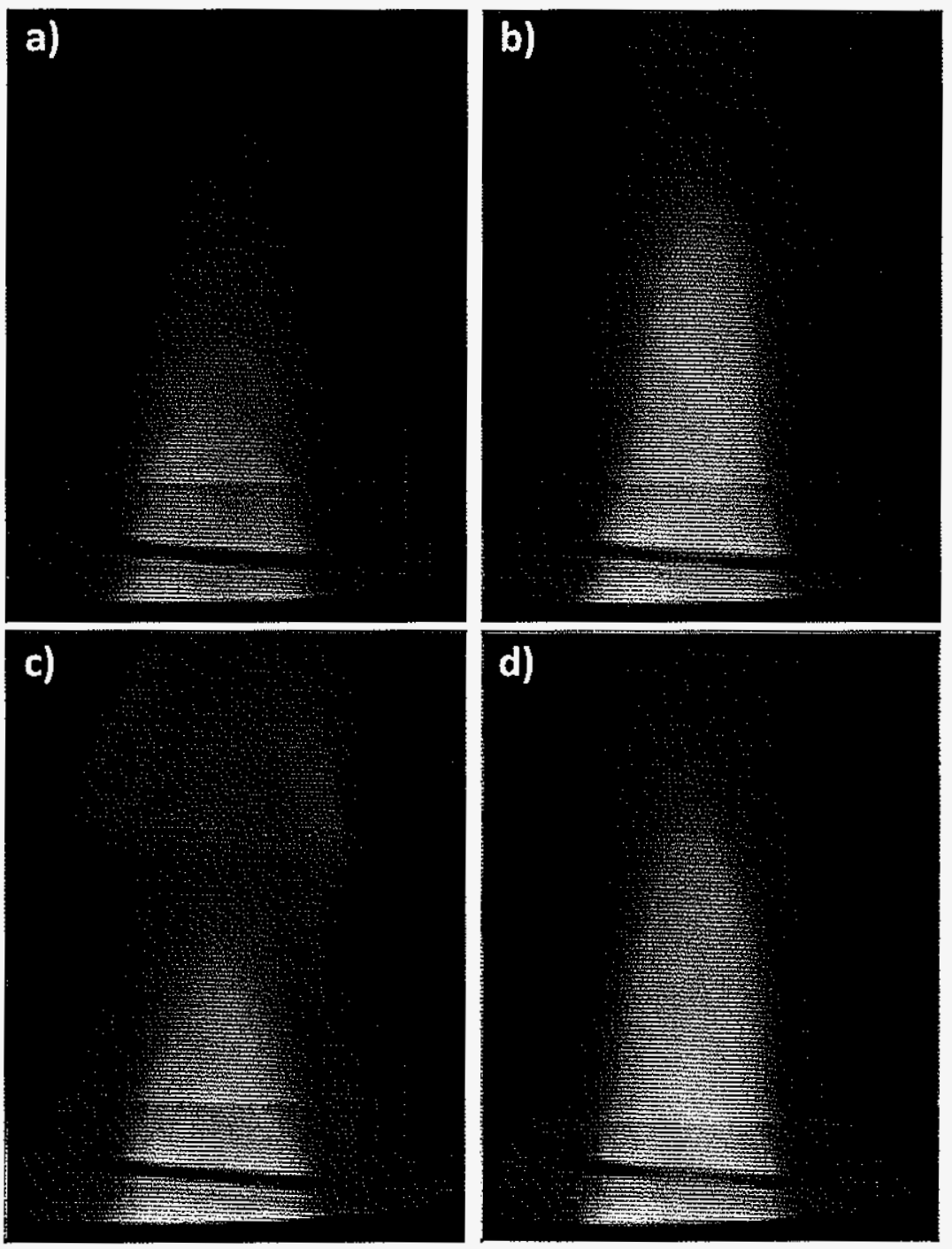

Figure 6. Photographs of an ICP with He sample gas a) with no sample introduction, and approximately $10 \mathrm{~s}$ after stopping introduction of b) $\mathrm{Na}, \mathrm{Ca}$, and $\mathrm{Si}$; ) $\mathrm{Na}$; d) $\mathrm{Ca}$. 

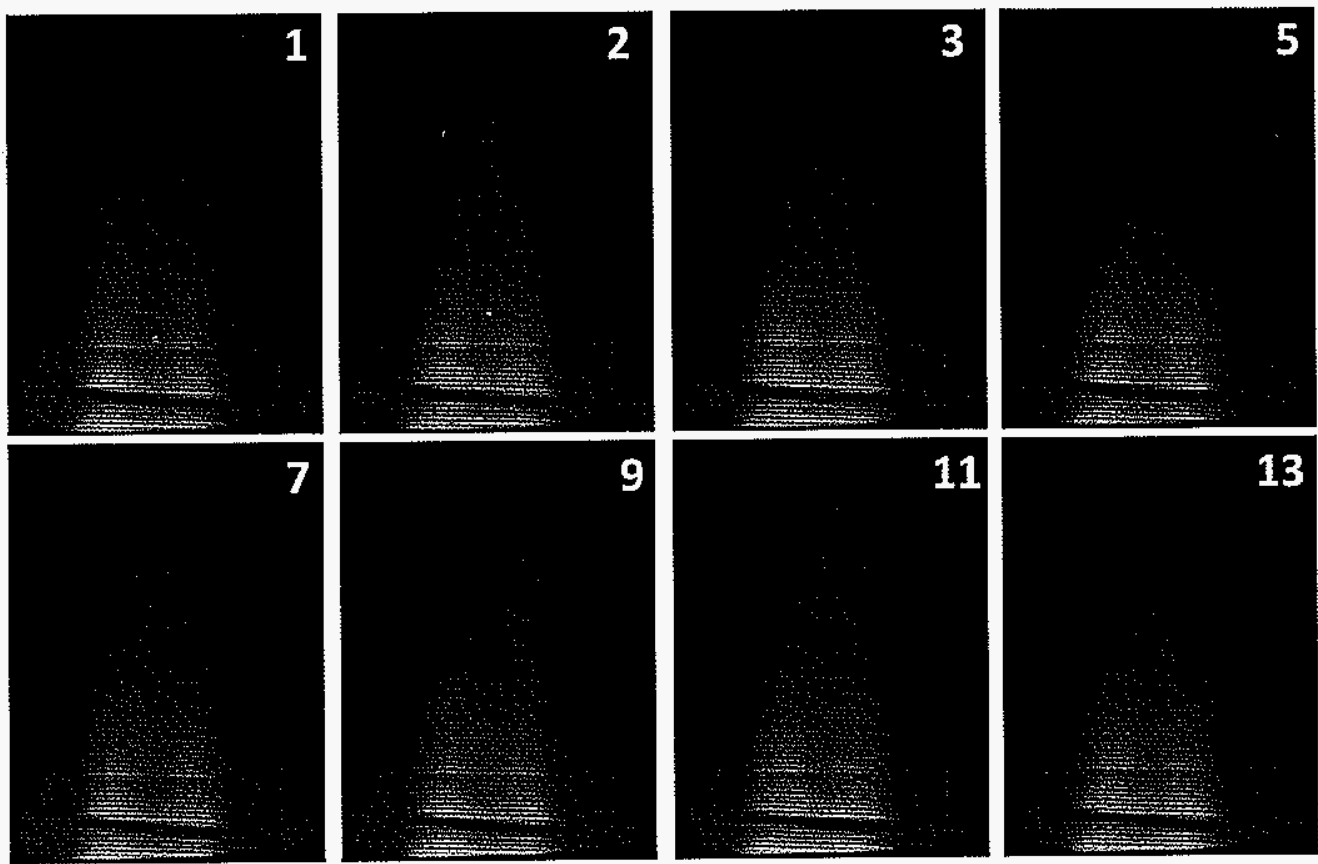

13

Figure 7. A single particle from laser ablation of NIST 610 glass in Ar. Relative frame numbers are shown. 

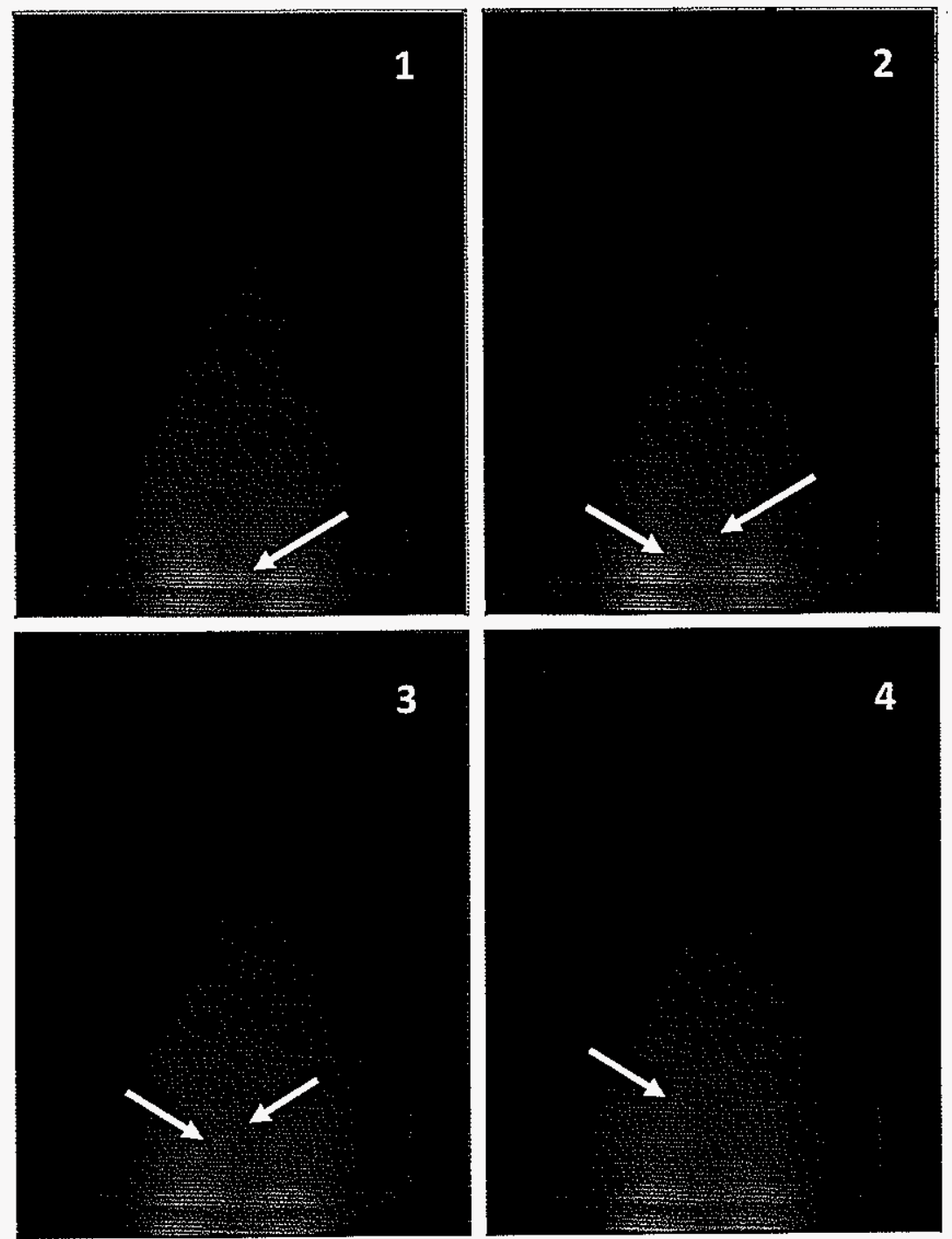

Figure 8. Two distinct particle clouds are visible from LA of NIST 610 glass in Ar showing distinct emission from $\mathrm{Na}$ and $\mathrm{Ca}$, respectively, at approximately the same axial position in the ICP. Relative frame numbers are shown. 

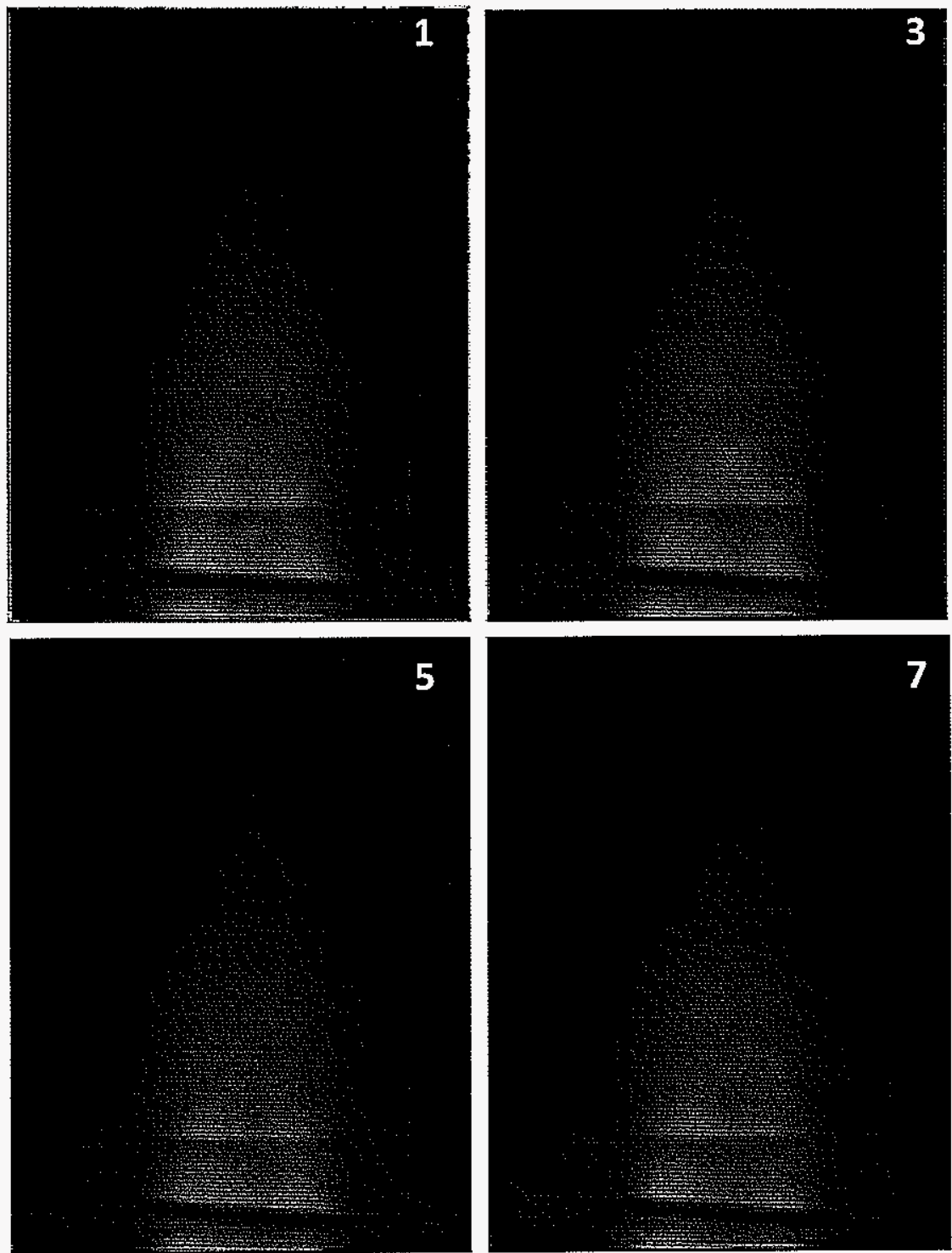

Figure 9. A typical emission cloud from a glass particle in He. Most particles from LA in He do not traverse the plasma intact. Relative frame numbers are shown. 


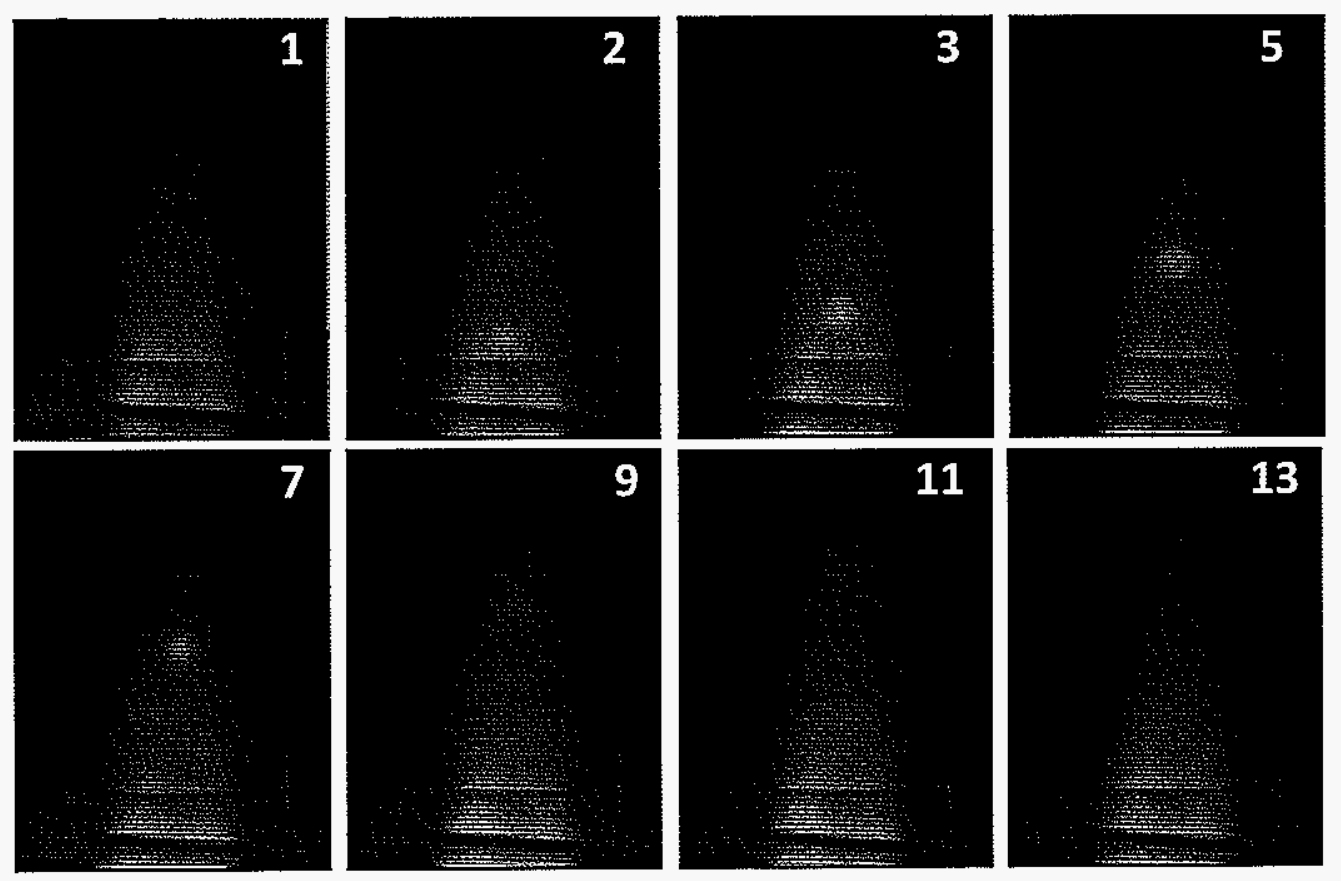

Figure 10. Ca emission is observed from a single larger particle from LA of NIST 610 glass in He. Particles of this size are not observed frequently. Relative frame numbers are shown. 


\title{
Chapter 4. A method for online detection of elemental release from live tissue in a physiological saline matrix using inductively coupled plasma mass spectrometry
}

\author{
A paper submitted for publication in Analytical and Bioanalytical Chemistry \\ Nathan J. Saetveit, Alan R. Kay, and R. S. Houk
}

\begin{abstract}
A method and apparatus are described that are designed for real-time, online detection of metal release from live tissue, particularly brain slices, in a physiological saline matrix with inductively coupled plasma mass spectrometry (ICP-MS). Transition metals Mn, $\mathrm{Fe}, \mathrm{Cu}$, and $\mathrm{Zn}$ are determined as well as the nonmetal $\mathrm{P}$. Metal release in this study is simulated by injecting standard solutions prior to a chamber that would house a slice of live neural tissue. Solution flows through the slice chamber at approximately $120 \mu \mathrm{L} \mathrm{min}{ }^{-1}$, and a magnetic sector ICP-MS device monitors selected transition metals every $2 \mathrm{~s}$. Sub $\mu \mathrm{g} \mathrm{L}^{-1}$ detection limits in a $60 \mu \mathrm{L}$ injection were found for most elements studied.
\end{abstract}

\section{Introduction}

It has long been believed that zinc is released from certain synaptic terminals during neuronal activity and may thus act as a neuro-modulator. Two cornerstones of the zincrelease hypothesis were published back-to-back by Assaf and Chung ${ }^{1}$ and Howell et al. ${ }^{2}$ in 1984. In both cases hippocampal slices were perfused with physiological saline. The effluent was analyzed by atomic absorption spectrometry, or by the detection of radioactive 
zinc that had been preloaded into the slices. These papers presented an effective strategy for estimating whether zinc is indeed released during the course of synaptic transmission.

The online brain slice perfusion method is particularly useful because it allows for the real-time detection of metal release from live slices. In previous incarnations of this experiment, the temporal resolution was restricted to approximately two minutes by the analytical sensitivity of the techniques employed. In the intervening years, significant strides have been made in elemental analysis, particularly in inductively coupled plasma mass spectrometry (ICP-MS), which is a very sensitive elemental analysis technique well suited for online analysis of a wide variety of elements. ${ }^{3-5}$ Since ICP-MS can detect $\mu g \mathrm{~L}^{-1}$ or lower levels of many elements in volumes as low as a few microliters in a time frame of a few seconds, it can be profitably applied to online brain slices.

In principle, metal release can be monitored by membrane impermeable fluorescent indicators in the extra cellular space. There is evidence from our previous studies that zinc is not released but is presented to the extracellular space coordinated to sites on the presynaptic membrane. ${ }^{6,7}$ If this is indeed true, a chelating metal indicator may remove zinc and give rise to what is in effect a spurious release event. ${ }^{8}$ This can be avoided by using a technique that does not deploy an active metal chelator at the site of externalization. In addition, an independent measurement technique is desirable, especially one that has multielement capabilities.

Zinc is not the only metal for which claims of release have been made. Reports of ${\text { both } \text { copper }^{9} \text { and manganese }}^{10}$ release have been published; however, little work has been done to substantiate these findings. Liquid chromatography in conjunction with ICP-MS is capable of detecting a number of elements in chromatographic peaks with little loss of peak 
definition. "In the present experiment, all transition metals found in significant quantities in the mammalian central nervous system (CNS), viz. $\mathrm{Fe}, \mathrm{Cu}, \mathrm{Mn}$ and $\mathrm{Zn}$, are detected, as well as the nonmetal $\mathrm{P}$ since it is also of biological interest.

Matrices containing high amounts of dissolved solids, such as physiological saline solutions, cause signal suppression in ICP-MS ${ }^{12-15}$ Many methods have been described for improving the analysis of samples with high matrix concentrations in ICP-MS ${ }^{16}$ Typically, matrix removal and preconcentration, ${ }^{17-19}$ flow injection, ${ }^{20-22}$ or a combination of these techniques is used. Matrix removal can be successful when conditions are available to remove the matrix ions without removing the desired analytes. Unfortunately, online removal of a saline matrix to determine transition metal concentrations in real-time with high temporal resolution is difficult. ${ }^{23}$ Offline and online column preconcentration and flow injection have been the focus of many recent investigations of elemental analysis in high matrix solutions, ${ }^{16}$ but they are better suited for determining the concentrations of trace elements in individual samples and lack the time resolution $(\sim 1 \mathrm{~s})$ desired in the present work. For a transient peak resulting from a discrete release of metals, as might occur from neural tissue, a faster technique is required.

Another problem with high matrix solutions in ICP-MS is the greater abundance of polyatomic interferences. The most common type of ICP-MS device, based on a quadrupole mass analyzer, is unable to separate polyatomic ions from monatomic ions at the same nominal mass. Advanced devices based on collision cells can successfully determine many elements with interferences, usually by attenuating interference ions relative to monatomic ions. ${ }^{24-27}$ The alternate approach is to use a high mass resolution spectrometer. The Thermo Element 1 magnetic sector ICP-MS device used in this study is able to separate most 
polyatomic interferences and permits direct measurement of atomic ions. ${ }^{28,29}$ In addition to this capability, the high sensitivity of this device enables real-time monitoring of analytes in a saline matrix without matrix removal, preconcentration, or flow injection, allowing realtime detection of peaks from simulated discrete transition metal release events.

The focus of this manuscript is to describe a method and apparatus that can be used to measure the stimulated release of transition metals from neural tissue in a physiological saline matrix in real-time. Response time and detection limits for various elements are estimated. Actual results from the slice chamber loaded with brain slices will be reported separately.

\section{Experimental}

\section{Chemicals and Materials}

The chemicals used were the highest purity commercially available. Sodium hydrogen carbonate (Puratronic) was purchased from Alfa Aesar (Ward Hill, MA). All other chemicals were purchased from Sigma-Aldrich (St. Louis, MO). Ultrapure nitric acid (Ultrex II, J.T. Baker, Phillipsburg, NJ) was used for cleaning and preparation of standards. All solutions were prepared with deionized water (18 M , Millipore Corporation, Bedford, MA) and stored in Nalgene, Teflon (PFA), or PTGE containers. Teflon syringes were used at first but proved permeable to $\mathrm{O}_{2}$, which diffused from the saline through the syringe into the atmosphere. Instead, all-plastic disposable 50-mL Luer-slip syringes (Thermo Fisher Scientific, Waltham, MA) were used, which were much less permeable to $\mathrm{O}_{2}$ and maintained the physiological quality of the saline matrix throughout the entire experiment. Teflon pipette tips were used to prepare the saline solutions. The experimental apparatus used 
fluoropolymer tubing and various fittings from Elemental Scientific, Inc. (Omaha, NE) and Upchurch Scientific (Oak Harbor, WA).

\section{Cleaning Procedures}

Metal contamination in the tubing, bottles, and syringes can be a large portion of background signal, so extensive cleaning procedures were used. All bottles, syringes, and pipette tips were repeatedly soaked in a dilute nitric acid bath and rinsed with deionized water. After these initial washes, the materials were cleaned by a nitric acid vapor wash and rinsed with deionized water. All cleaned parts were stored in a class 100 laminar flow clean hood (Design Filtration Inc., Ottawa, Ontario) until used in the experiment. Dilute nitric acid was pumped through the sample apparatus for at least eight hours prior to the experiment to remove as many contaminants as possible.

\section{Solution Preparation}

The compositions of the normal saline and high $\mathrm{K}$ saline solutions are listed in Table 1. Solutions were prepared by adding the appropriate amounts of $\mathrm{NaCl}, \mathrm{KCl}, \mathrm{NaHCO}_{3}$, and glucose followed by bubbling with $95 / 5 \% \mathrm{O}_{2} / \mathrm{CO}_{2}$ for approximately 10 minutes, sufficient time for the $\mathrm{CO}_{2}$ to bring the solution to $\mathrm{pH} 7.4$ and for $\mathrm{O}_{2}$ to reach saturation. Gas was dispersed through a plastic Aqua-Tech air diffuser (Regent Pet Products, Moorpark, CA). Finally, $\mathrm{MgCl}_{2}$ and $\mathrm{CaCl}_{2}$ were added and the solution was bubbled with $95 / 5 \% \mathrm{O}_{2} / \mathrm{CO}_{2}$. Solutions were either continuously bubbled or stored in Nalgene PET (polyethylene terephthalate) bottles until loaded in the syringes. 
Each standard was prepared by spiking the appropriate amount of $1 \mathrm{mg} \mathrm{L}^{-1}$ multielement stock solution containing $\mathrm{P}, \mathrm{S}, \mathrm{Mn}, \mathrm{Fe}, \mathrm{Cu}$, and $\mathrm{Zn}$ into the high $\mathrm{K}$ saline. The stock solution was prepared from individual $1000 \mathrm{mg} \mathrm{L}^{-1}$ aqueous elemental standards (SPEX CertiPrep, Metuchen, NJ).

\section{Slice Chamber and Flow System}

Figure 1 shows the slice chamber and flow system. A syringe pump (NE-500 OEM, New Era Pump Systems, Inc., Wantagh, NY) containing normal saline pumps at $120 \mu \mathrm{L} / \mathrm{min}$ into a six port injection valve (Cheminert, Elemental Scientific, Inc., Omaha, NE) fitted with a $60 \mu \mathrm{L}$ injection loop. At the start of the experiment, the normal saline solution bypasses the loop and flows through the empty slice chamber. After 5 minutes, a high $\mathrm{K}$ solution with a spike of known concentrations of the analytes is injected.

The slice chamber consists of a custom-made Plexiglas union with an ID of approximately $22 \mathrm{~mm}$ into which Upchurch P-218 fittings are secured. In an earlier version of the slice chamber described in this paper, the entire slice chamber was machined from Plexiglas so it would be transparent. Unfortunately, the Plexiglas adsorbed some elements, which caused significant broadening and longer washout times. In addition, the Plexiglas contributed to somewhat higher background levels of many elements. To prevent solution from touching the Plexiglas, the standard ferrules for the Upchurch P-218 fittings were replaced with custom-made Teflon ferrules machined with outer diameters to fit snugly in the union. The ferrules on the inlet and outlet sides of the chamber meet and seal in the center and create an all-Teflon slicc chamber in the interior space. The Plexiglas union makes it possible to visually monitor the sample inside the slice chamber as the chamber is closed by 
pressing the ferrules together from both sides. Once the chamber is closed, the slice cannot be seen. The resulting slice chamber has a short cylindrical center channel and conical ends. The flow system and slice chamber is a closed perfusion system, which prevents the loss of oxygen that occurs rapidly in the open chambers used in most physiological experiments.

After the slice chamber, the solution passes through a Millex-HV filter $(0.45 \mu \mathrm{m}$ pore diameter, Millipore Corporation, Bedford, MA) to filter whole cells or particulate matter that might leave the tissue. The solution then flows into a PEEK 4-way cross (Upchurch Scientific, Oak Harbor, WA), into which also flow two equal $80 \mu \mathrm{L} / \mathrm{min}$ streams of nitric acid containing approximately $1 \mu \mathrm{g} \mathrm{L}^{-1} \mathrm{Ga}$. The Ga standard is added via two flows into opposite ends of the cross to prevent large, slow undulations in signal observed when using a $\mathrm{Y}$ connector or 3-way tee and a single source of Ga standard solution. The addition of the $\mathrm{Ga} / \mathrm{HNO}_{3}$ solution brings the total liquid flow rate to $\sim 280 \mu \mathrm{L} \mathrm{min}^{-1}$, diluting the original saline by factor of $\sim 2.3$.

\section{Sample Introduction}

A PFA Teflon self-aspirating nebulizer with a natural uptake rate of approximately $200 \mu \mathrm{L} / \mathrm{min}$ and a double pass spray chamber (internal volume $200 \mathrm{~cm}^{3}$, Elemental Scientific, Inc., Omaha, NE) were used for sample introduction into the ICP-MS. The nebulizer uptake tube was coupled loosely to the exit of the cross with an Upchurch P-218 male fitting that was left snug and was not tightened down onto the female exit of the cross. Thus the nebulizer still self-aspirated and a small amount of excess solution could seep out the edge of the fitting to waste. Allowing natural uptake by the nebulizer led to a much more 
stable signal than that obtained by tightening the Upchurch fitting onto the uptake tube and forcing the solution through the nebulizer.

\section{Instrumentation.}

The ICP-MS device was a magnetic sector double focusing instrument ${ }^{11,30}$ (Elementl, Thermo Finnigan, Bremen, Germany) operated in medium resolution $(\mathrm{m} / \Delta \mathrm{m}=$ $4,000)$ to resolve elements of interest from numerous polyatomic interferences resulting from the saline matrix and gases present in the plasma. The sample gas flow rate was tuned for a balance between sensitivity and signal stability for the elements of interest. Table 2 summarizes the ICP-MS operating conditions and the isotopes measured.

\section{Data Analysis}

Plots of integrated signal versus time were prepared for each isotope and injection. Each scan through the mass range took approximately 2 seconds. Data were collected for approximately 20 minutes per injection; the sample was introduced at the 5 minute mark. Integrated signals from each isotope for each ICP-MS scan were plotted versus time. Data were smoothed using Tukey's method (3RSSH), ${ }^{31}$ and the areas and heights of the signal transients were determined from the time profiles. Peak height was found to have the most consistent response to concentration change. 


\section{Results and Discussion}

\section{Matrix Effects}

The dilution of the saline with nitric acid before nebulization reduces detrimental matrix effects and cone clogging. Flow ratios of saline to nitric acid between $1: 1$ and $1: 2$ were examined. Ratios near $1: 1$ led to cone clogging after a few hours; a ratio of 2:3 was found to be optimum. The forward RF power used in this experiment $(1350 \mathrm{~W})$ was higher than the typical $1200 \mathrm{~W}$ used on this instrument in our laboratory. In addition to dilution

with nitric acid, higher forward RF power may help prevent cone deposition and clogging. ${ }^{12}$ The plasma conditions resulting from matrix dilution and higher forward RF power led to relatively low levels of deposition and no clogging at the tips of the sampler and skimmer cones throughout the entire experiment.

Previous studies have shown that the addition of carbon to the plasma by adding compounds such as glucose, glycerol, or acetone to the solution or by adding methane or propane to the spray chamber may lessen cone deposition and increase sensitivity for some elements. ${ }^{21,32-34}$ Glucose is required in this experiment to maintain the viability of the biological preparations; its potential analytical benefits were not examined.

The average Ga signal (Fig. 2a) near the beginning of each run is used to correct for any variations of instrumental sensitivity during the experiment. There is a slight but steady reduction in signal over many hours during the experiment attributed to decreased sample flow through the nebulizer. After nebulizing the saline matrix continuously for $\sim 10$ to 12 hours, the nebulizer needed to be unclogged by removing it and briefly blocking and unblocking the tip. The steady decrease in signal due to nebulizer clogging throughout the experiment is easily corrected for by comparing the Ga signal in the blank injection to the $\mathrm{Ga}$ 
signal in each subsequent injection. In addition to acting as a standard, the steady state presence of $\mathrm{Ga}$ in the nitric acid allows monitoring of the overall stability of the system and provides a fast indication of any problems with the syringe pumps or connections in the apparatus.

\section{Peak Position}

Although the timing of the injection is known in this experiment, a $15 \%$ mass window of ${ }^{39} \mathrm{~K}^{+}$is measured to observe when the high $\mathrm{K}$ saline solution reached the plasma. Complete separation of ${ }^{39} \mathrm{~K}^{+}$from ${ }^{38} \mathrm{ArH}^{+}$requires spectral resolution of at least $\mathrm{m} / \Delta \mathrm{m}=$ 5700 , compared to the value of $\sim 4000$ used here. Nevertheless, a clear increase in the ${ }^{39} \mathrm{~K}^{+}$ signal is observed when the high $\mathrm{K}$ solution reaches the plasma (Fig. 2b). The large ${ }^{39} \mathrm{~K}^{+}$ peak provides insights into broadening induced by the apparatus. While not essential in this study, the monitoring of ${ }^{39} \mathrm{~K}^{+}$will be useful during experiments with live neural tissue samples to mark the time that the stimulating high $\mathrm{K}$ solution reaches the biological sample.

\section{Sample Pathway}

An inert sample pathway is crucial in ensuring the lowest possible background contamination and preventing chemical interaction between analytes and the apparatus. The Teflon slice chamber led to lower background contamination and no observable analyte retention.

Minimizing dead volume in the flow system is another important parameter to optimize the sample pathway to lessen broadening. Since the Millex-HV filter causes significant backpressure, the tubing diameter $(0.5 \mathrm{~mm} \mathrm{ID})$ was selected to be as narrow as 
possible without contributing greatly to the backpressure. Most of the dead volume, approximately $50 \mu \mathrm{L}$, is from the slice chamber. This dead volume was minimized by making the cylindrical center as short as possible but still large enough to hold a biological sample without damaging it. The conical entrance and exit to the slice chamber allow solution to pass through and around the entire area of the slice at the center of the chamber while not dramatically increasing the volume. Finally, the tubing lengths were minimized throughout the sample apparatus to have the shortest possible pathway.

\section{Time Profiles}

Figure 2a shows signal $v s$. time plots for a $\sim 2 \mu \mathrm{g} \mathrm{L} L^{-1}$ standard injection. Each element is measured for approximately $300 \mathrm{~ms}$ every $2 \mathrm{~s}$, which provides a sampling frequency high enough to detect transient signals on a time scale appropriate for this experiment. The ${ }^{39} \mathrm{~K}^{+}$ peak is shown in Figure 2b.

\section{Limit of Detection}

Five-point external calibration curves were created for each element using peak heights from the time profiles (Figure 3). Peak heights in each injection were corrected for drift in instrumental sensitivity by multiplying each maximum peak height by the ratio of the average Ga signal in the blank injection to the average $\mathrm{Ga}$ signal in that injection. The average $\mathrm{Ga}$ signal in each injection was found by averaging the data acquired in the 2 minutes immediately prior to the appearance of the analyte peaks in the time profile. Injections of high $\mathrm{K}$ saline with no added standard showed slightly elevated concentrations of $\mathrm{P}$ and $\mathrm{Cu}$ relative to the normal saline, indicating more contamination for these elements in 
the $\mathrm{KCl}$ stock solution. Any minor peaks present in the blank injection were subtracted from the calculated peak heights. Each standard solution was injected three times, with standard concentrations ranging from approximately $0.5-8.0 \mu \mathrm{g} \mathrm{L}^{-1}$. Despite the saline matrix and some elements with relatively low ionization efficiency and/or lower isotopic abundance, $\mathrm{R}^{2}$ values $\geq 0.99$ were obtained for the calibration curves for all elements observed (Table 3).

Table 3 also shows detection limits in a $60 \mu \mathrm{L}$ injection that were calculated for each element by two different methods. First, detection limits were calculated using the most common definition for detection limit: the analyte concentration that yields a net signal of three times the standard deviation of the background signal, $3 s_{b}$. Alternatively, the signal detection limit $y_{d l}$ is calculated from the relation:

$$
y_{d l}=b+3 s_{y}
$$

where $b$ and $s_{y}$ are the y-intercept and standard deviation from the least-squares equation for each calibration curve. This expression becomes $3 s_{y} / m$ in concentration units, where $m$ is the slope of the calibration curve..$^{35-37}$

Both of these calculations provide reasonable approximations of the detection limit capabilities for this method, and the different calculations provide similar results. The detection limits calculated from calibration curve statistics tended to be better than those calculated by the standard deviation of the background for elements with lower signal, such as $\mathrm{P}, \mathrm{S}$, and $\mathrm{Zn}$, but these elements had worse detection limits than elements with higher signal. Most significantly, detection limits for most elements observed are $\leq 1 \mu \mathrm{gL}^{-1}$. As usual for ICP-MS analyses, the detection limits were mainly limited by the purity of the salts and the cleanliness of the apparatus and instrument. 
The detection limits estimated in this experiment are conservative because additional broadening of the standard peaks occurs in the tubing between the injection loop and the slice chamber, as well as in the inlet area of the slice chamber. Only broadening after the neural tissue - in the exit of the slice chamber and the tubing between the slice chamber and the nebulizer - would matter in the intended experiments with live neural tissue.

\section{Conclusions}

This paper demonstrates a method and apparatus suitable for real-time ICP-MS detection of stimulated transient metal release from neural tissue with detection limits for most elements of $1 \mu \mathrm{g} \mathrm{L}^{-1}$ or better in a $60 \mu \mathrm{L}$ injection. Assaf and Chung reported a $\mathrm{Zn}$ release in rat neural tissue greater than $10 \mu \mathrm{g} \mathrm{L}^{-1}$ over the first few minutes of stimulation with high $\mathrm{K}$ solution, which would be easily detectable with this technique. Coupling live tissue to ICP-MS provides the rare opportunity to perform physiological experiments in realtime with a powerful analytical technique with low detection limits.

The sampling rate, while adequate for the goals of this experiment, could be improved by monitoring fewer elements or using smaller peak windows, fewer samples per peak, or shorter dwell times. Approximately half of the time required for each scan through the mass range in this experiment is taken by the magnet settling time, the time for the magnetic field to stabilize when jumping to a new mass range, so the only way to sample faster than $\sim 1 \mathrm{~Hz}$ is to decrease the number of magnet jumps by monitoring fewer elements.

The timing of the high $\mathrm{K}$ saline could be monitored by measuring ${ }^{39} \mathrm{~K}^{16} \mathrm{O}^{+}$, which is resolved spectrally from ${ }^{55} \mathrm{Mn}^{+}$. If only ${ }^{64} \mathrm{Zn}^{+}$and ${ }^{69} \mathrm{Ga}^{+}$were monitored, no magnet jump would be required and each isotope could be monitored for roughly $200 \mathrm{~ms}$ every $400 \mathrm{~ms}$ under the 
conditions of this experiment. By decreasing the peak windows to $50 \%$ (from $100 \%$ ) and the samples per peak to 10 (from 20), these two elements could each be monitored for $50 \mathrm{~ms}$ every $100 \mathrm{~ms}$. Additionally, the newer version of the ICP-MS device, the Element2, has faster magnet scanning capabilities that would improve the sampling rate. Since shot noise is more significant if fewer ions are collected, the parameters in this experiment were chosen to give an appropriate balance between speed and shot noise.

Future studies will include apparatus refinements and results from the stimulation of live brain slices. The slice chamber may be modified to accommodate different samples. This technique is easily adaptable for use with larger injection loops. Alternatively; reproducible injections of any volume can be made using computer-controlled, timed injections from a constant supply of high $\mathrm{K}$ saline. Moreover, the technique can be applied to any organ that is viable in slice form or to immobilized cells that discharge transition metals such as the beta cells of the pancreas which co-release zinc with insulin. ${ }^{38,39}$

\section{Acknowledgements}

Ames Laboratory is operated for the U. S. Department of Energy (USDOE) by lowa State University of Science and Technology under Contract No. DE-AC02-07CH11358. This research was supported in part by funds from the NINDS (NS-47508) to ARK. The authors would like to thank Dan Wiederin and Elemental Scientific, Inc. for the injection loop and useful discussions. 


\section{References}

1. S. Y. Assaf and S. H. Chung, Nat, 1984, 308, 734-736.

2. G. A. Howell, M. G. Welch and C. J. Frederickson, Nat, 1984, 308, 736-738.

3. R. S. Houk and J. J. Thompson, Mass Spectrom. Rev., 1988, 7, 425-461.

4. K. E. Jarvis, A. L. Gray and R. S. Houk, Handbook of Inductively Coupled Plasma Mass Spectrometry, Chapman and Hall, New York. 1992.

5. R. S. Houk, V. A. Fassel, G. D. Flesch, H. J. Svec, A. L. Gray and C. E. Taylor, in Anal Chem. 1980, vol. 52, pp. 2283-2289.

6. A. R. Kay, J Neurosci, 2003, 23, 6847-6855.

7. A. R. Kay and K. Tóth, J Neurophysiol, 2006, 95, 1949-1956.

8. A. R. Kay, Trends Neurosci, 2006, 4, 200-206.

9. M. L. Schlief, A. M. Craig and J. D. Gitlin, J Neurosci, 2005, 25, 239-246.

10. A. Takeda, N. Sotogaku and N. Oku, Neuroscience, 2002, 114, 669-674.

11. R. S. Houk, in Handbook of Elemental Speciation, ed. R. Cornelius, J. Caruso, H. Crews and K. Heumann, John Wiley \& Sons. 2002.

12. D. J. Douglas and L. A. Kerr, J Anal At Spectrom, 1988, 3, 749-752.

13. J. A. Olivares and R. S. Houk, Anal. Chem., 1986, 58, 20-25.

14. H. Xie, X. Nie and Y. Tang, Chin. J. Anal. Chem., 2006, 34, 1570-1574.

15. D. Beauchemin, J. W. McLaren, A. P. Mykytiuk and S. S. Berman, Anal. Chem., $1987,59,778-783$.

16. T. P. Rao, P. Metilda and J. M. Gladis, Crit Rev Anal Chem, 2005, 35, 247-288.

17. E. M. Heithmar, T. A. Hinners, J. T. Rowan and J. M. Riviello, Anal. Chem., $1990,62,857-864$. 
18. D. B. Taylor, H. M. Kingston, D. J. Nogay, D. Koller and R. Hutton, J Anal At Spectrom, 1996, 11, 187-191.

19. J. Wu and E. A. Boyle, Anal. Chem., 1997, 69, 2464-2470.

20. C. T. Gross and R. S. Houk, Anal. Chem., 2008, submitted.

21. M. P. Field, M. LaVigne, K. R. Murphy, G. M. Ruiz and R. M. Sherrell, J Anal At Spectrom, 2007, 22, 1145-1151.

22. A. E. Holliday and D. Beauchemin, J Anal At Spectrom, 2003, 18, 1109-1112.

23. Y. T. Chung, Y. C. Ling, C. S. Yang, Y. C. Sun, P. L. Lee, C. Y. Lin, C. C. Hong and M. H. Yang, Anal. Chem., 2007, 79, 8900-8910.

24. S. D. Tanner and V. I. Baranov, J Am Soc Mass Spectrom, 1999, 10, 1083-1094.

25. S. D. Tanner, V. I. Baranov and U. Vollkopf, J Anal At Spectrom, 2000, 15, 12611269.

26. J. T. Rowan and R. S. Houk, Appl Spectrosc, 1989, 43, 976-980.

27. M. Grotti and R. Frache, J Anal At Spectrom, 2007, 22, 1481-1487.

28. I. Rodushkin and T. Ruth, J Anal At Spectrom, 1997, 12, 1181-1185.

29. M. P. Field, J. T. Cullen and R. M. Sherrell, J Anal At Spectrom, 1999, 14, 14251431.

30. L. Moens and N. Jakubowski, Anal. Chem., 1998, 70, 251A-256A.

31. J. W. Tukey, Exploratory Data Analysis, Addison-Wesley, Reading, MA. 1977.

32. P. Allain, L. Jaunault, Y. Mauras, J. M. Mermet and T. Delaporte, Anal. Chem., $1991,63,1497-1498$.

33. Z. Hu, S. Hu, S. Gao, Y. Liu and S. Lin, Spectrochim. Acta Part B, 2004, 59, $1463-1470$. 
34. I. Rodushkin, P. Nordlund, E. Engström and D. C. Baxter, J Anal At Spectrom, 2005, $20,1250-1255$.

35. G. L. Long and J. D. Winefordner, Anal. Chem., 1983, 55, 712A-724A.

36. M. E. Zorn, R. D. Gibbons and W. C. Sonzogni, Environ Sci Technol, 1999, 33, 2291-2295.

37. W. R. Porter, Anal. Chem., 1983, 55, 1290A.

38. W.-J. Qian, K. R. Gee and R. T. Kennedy, Anal. Chem., 2003, 75, 3468-3475.

39. K. R. Gee, Z.-L. Zhou, W.-J: Qian and R. Kennedy, JACS, 2002, 124, 776-778. 
Table 1. Saline composition

\begin{tabular}{lcc} 
Component & $\begin{array}{c}\text { Normal Saline] } \\
(\mathrm{mM})\end{array}$ & $\begin{array}{c}\text { [High K saline] } \\
(\mathrm{mM})\end{array}$ \\
\hline $\mathrm{NaCl}$ & 124 & 101.5 \\
$\mathrm{KCl}$ & 2.5 & 25 \\
$\mathrm{CaCl}_{2}$ & 2 & 2 \\
$\mathrm{MgCl}_{2}$ & 2 & 2 \\
$\mathrm{NaHCO}_{3}$ & 26 & 26 \\
Glucose & 10 & 10 \\
& & \\
\hline
\end{tabular}


Table 2. ICP-MS operating conditions

Resolution mode

Torch

Outer gas flow rate

Auxiliary gas flow rate

Sample gas flow rate

Forward if power

Detector mode

Mass window

Sampling time

Samples per peak

Isotopes measured
Medium $(m / \Delta m=4000)$

Shielded, shield grounded

$16 \mathrm{~L} \mathrm{~min}^{-1}$

$0.85 \mathrm{~L} \mathrm{~min}^{-1}$

$1.05 \mathrm{~L} \mathrm{~min}^{-1}$

$1350 \mathrm{~W}$

Counting

$100 \%$

$0.01 \mathrm{~s}$

20

${ }^{31} \mathrm{P},{ }^{55} \mathrm{Mn},{ }^{56} \mathrm{Fe}$,

${ }^{63} \mathrm{Cu},{ }^{64} \mathrm{Zn},{ }^{69} \mathrm{Ga}$ 
Table 3. Calibration curve statistics and detection limits in $60 \mu \mathrm{L}$ injection

\begin{tabular}{|c|c|c|c|c|c|c|c|}
\hline \multirow[b]{3}{*}{ Element } & \multirow[b]{3}{*}{$\mathrm{m}$} & \multirow[b]{3}{*}{$b$} & \multirow[b]{3}{*}{$\mathrm{R}^{2}$} & \multicolumn{4}{|c|}{ Detection limits } \\
\hline & & & & \multicolumn{2}{|c|}{$3 s_{b}$} & \multicolumn{2}{|c|}{$3 s_{y} / m$} \\
\hline & & & & $\mu g L^{-1}$ & $\mathrm{nM}$ & $\mu \mathrm{g} \mathrm{L}^{-1}$ & $\mathrm{nM}$ \\
\hline$P$ & 1,550 & 114 & 0.9960 & 1.3 & 40 & 0.7 & .20 \\
\hline $\mathrm{Mn}$ & 22,500 & $-2,290$ & 0.9994 & 0.4 & 7 & 0.3 & 5 \\
\hline $\mathrm{Fe}$ & 14,700 & 346 & 0.9904 & 0.6 & 11 & 1.2 & 20 \\
\hline $\mathrm{Cu}$ & 7,650 & -34 & 0.9982 & 0.4 & 6 & 0.5 & 8 \\
\hline $\mathrm{Zn}$ & 3,130 & 1,240 & 0.9951 & 1.2 & 20 & 0.8 & 12 \\
\hline
\end{tabular}



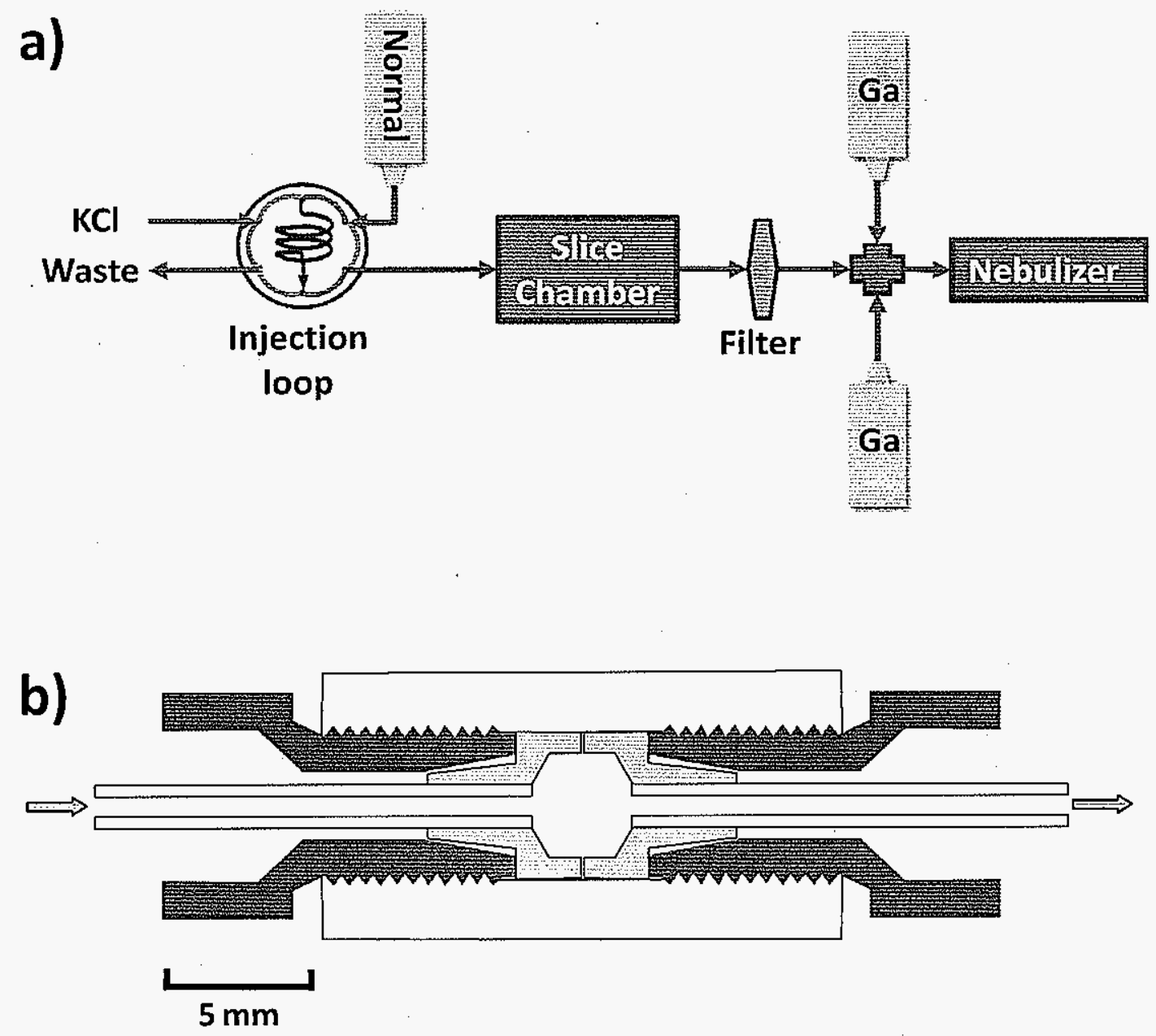

Figure 1. A diagram of the flow system (a) and a cross section of the slice chamber (b). 
a)

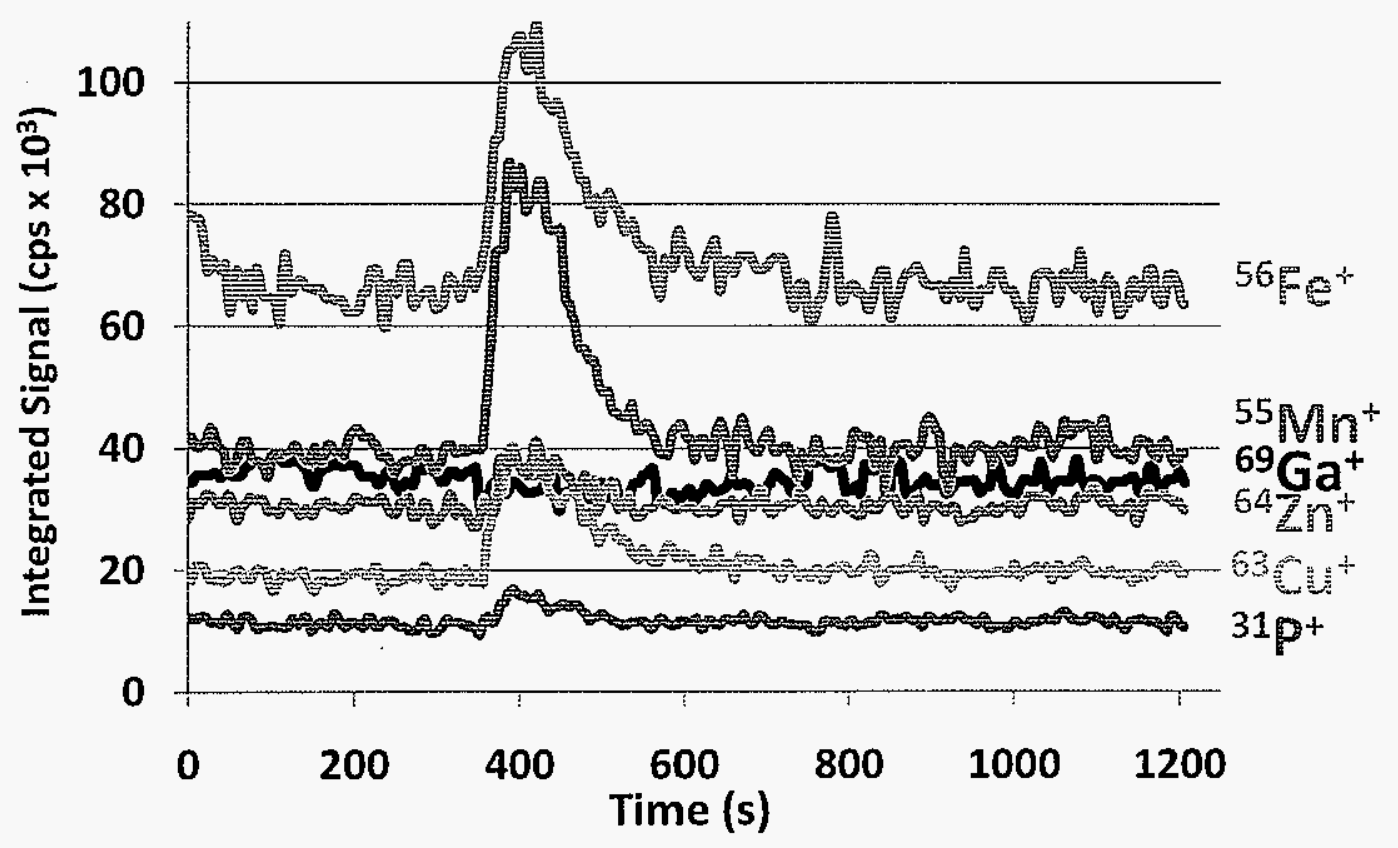

b)

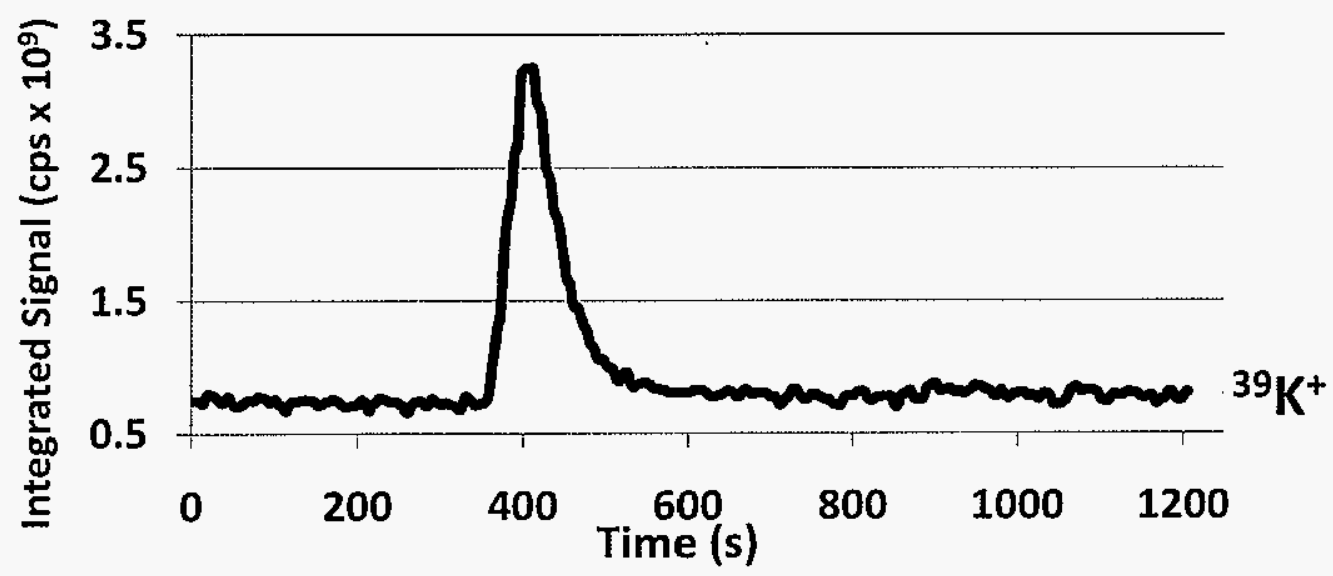

Figure 2. Time profiles from $60 \mu \mathrm{L}$ injection of high $\mathrm{K}$ saline with standards: a) $\sim 2 \mu \mathrm{g} \mathrm{L}^{-1}$ standard injection and $\mathrm{b}){ }^{39} \mathrm{~K}^{+}$peak indicating when the injection reaches the ICP. Injection of $60 \mu \mathrm{L}$ of high $\mathrm{K}$ saline spiked with standard occurred at approximately $300 \mathrm{~s}$. 


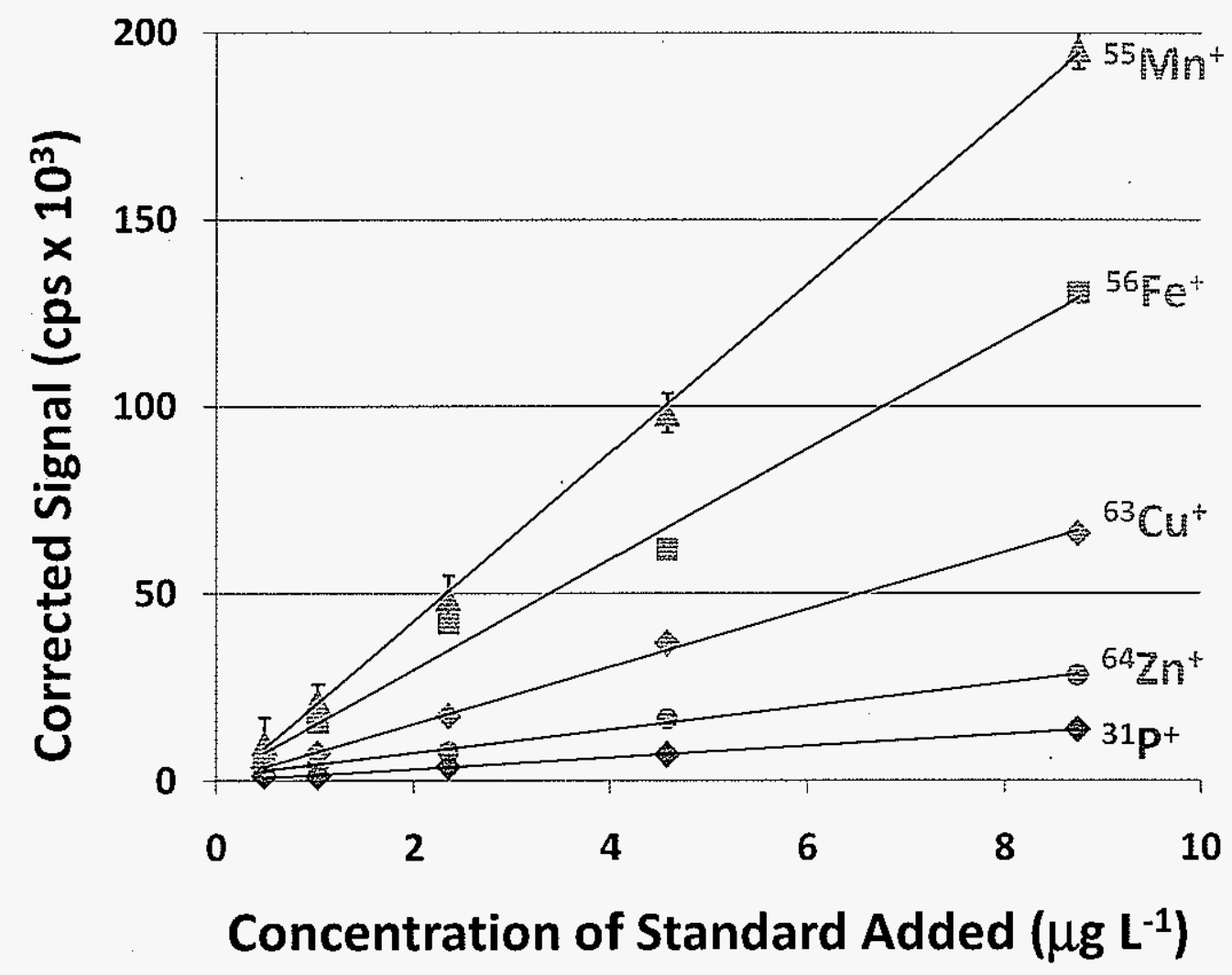

Figure 3. Calibration curves derived from peak heights in time profiles. 


\section{Chapter 5. General Conclusions}

ICP-MS continues to be a rich source of research material even as it matures as a technique. Fundamental studies of LA-ICP-MS are important to augment understanding of fractionation and improve analyses with LA-ICP-MS. The study presented in Chapter 2 adds to the growing understanding of fractionation and shows clear differences between ns and fs LA aerosols with a fast, online method. The photographic study of individual particles in an ICP reveals ICP-induced sources of fractionation. As fractionation becomes more understood and controlled, the use of LA will expand more quickly into routine settings for solid sample analysis. Since LA-ICP-MS requires very little or no sample preparation, it is a very cost- and time-effective method of analysis to replace cumbersome analyses involving sample dissolution and other preparation.

The advantages of high sensitivity and high resolution with magnetic sector ICP-MS makes it a natural pair with many types of sample introduction, including LA and solution nebulization. The work described in Chapter 4 would not be possible with ICP-MS without the high resolution capabilities and sensitivity of the magnetic sector device to overcome matrix interferences.

There are many exciting avenues for further research in this field. Further studies involving fs LA may be pursued on a variety of substrates including metals, silicates, or any other materials of interest. Understanding and minimizing the sources of fractionation or developing methods to calibrate for the presence of fractionation continue to be important goals for LA studies. Future high-speed photographic studies may focus on aerosols from fs LA of metals or silicates to elucidate the vaporization behavior of large agglomerations of 
small particles and seek explanations of fractionation behavior previously documented with fs LA. Magnetic sector ICP-MS will continue to be an important tool whenever the presence of matrix ions interferes with analyte ions of interest. Of special interest will be results from the stimulation of live neural tissue and further applications of the apparatus for online detection of elemental release. 


\section{Acknowledgements}

This work was performed at Ames Laboratory under Contract No. DE-AC0207CH11358 with the U.S. Department of Energy (USDOE). The United States government has assigned the DOE Report number IS- $\Upsilon 2468$. This work was supported by the USDOE,

Office of Defense Nuclear Nonproliferation, Office of Nonproliferation Research and Engineering, NA-22.

This dissertation would not have been possible without the support of countless people. I would like to thank my major professor, Dr. R. S. Houk, for his guidance. I owe many thanks to all past and present Houk group members, research collaborators, teachers and professors, and friends and family. I especially wish to thank my parents for their steady encouragement throughout my life and my wife, Deb, for her tireless love and support every day. 